\title{
First observations of SPEAR-induced artificial backscatter from CUTLASS and the EISCAT Svalbard radars
}

\author{
T. R. Robinson ${ }^{1}$, T. K. Yeoman ${ }^{1}$, R. S. Dhillon ${ }^{1}$, M. Lester ${ }^{1}$, E. C. Thomas ${ }^{1}$, J. D. Thornhill ${ }^{1}$, D. M. Wright ${ }^{1}$, A. P. van \\ Eyken $^{2}$, and I. W. McCrea ${ }^{3}$ \\ ${ }^{1}$ Department of Physics and Astronomy, University of Leicester, Leicester LE1 7RH, UK \\ ${ }^{2}$ EISCAT Scientific Association, Box 164, 98123 Kiruna, Sweden \\ ${ }^{3}$ Department of Space Science and Technology, Rutherford-Appleton Laboratories, Chilton, Oxfordshire OX11 0QX, UK
}

Received: 13 April 2005 - Revised: 8 December 2005 - Accepted: 14 December 2005 - Published: 7 March 2006

\begin{abstract}
Results are presented from the first two active experimental campaigns undertaken by the new SPEAR (Space Plasma Exploration by Active Radar) high-power system that has recently become operational on Spitzbergen, in the Svalbard archipelago. SPEAR's high-power beam was used to excite artificial enhancements in the backscatter detected by the ESR (EISCAT Svalbard Radar) parallel to the geomagnetic field, as well as coherent backscatter detected by both of the CUTLASS (Co-operative UK Twin Located Auroral Sounding System) coherent radars, in directions orthogonal to the geomagnetic field. The ESR detected both enhanced ion-lines as well as enhanced plasma-lines, that were sustained for the whole period when SPEAR was transmitting ordinary mode radio waves, at frequencies below the maximum F-region plasma frequency. On a number of occasions, coherent backscatter was also observed in one or in both of the CUTLASS radars, in beams that intersected the heated volume. Although the levels of enhanced backscatter varied considerably in time, it appeared that ion-line, plasma-line and coherent backscatter were all excited simultaneously, in contrast to what has typically been reported at Troms $\varnothing$, during EISCAT heater operations. A description of the technical and operational aspects of the new SPEAR system is also included.
\end{abstract}

Keywords. Ionosphere (Active experiments; Plasma waves and instabilities; Instruments and techniques)

\section{Introduction}

High-power ground-based HF radio transmitters (heaters) have played an important role, over the past few decades, in the investigation of nonlinear wave interactions in space plasmas. From the earliest experiments at Platteville, Colorado (Minkoff et al., 1974) and at Arecibo, Puerto Rico (Gordon and Carlson, 1974) it became clear that large amplitude

Correspondence to: T. R. Robinson

(txr@ion.le.ac.uk) electromagnetic waves from heaters could excite a variety of plasma instabilities which caused the amplification of smallscale electrostatic plasma modes in the ionosphere that were then detectable as enhanced radar backscatter. Two broadly distinguishable types of artificially enhanced scatter are observed during the interaction of an ordinary mode (O-mode) heater wave with the ionosphere. The first involves scatter from small-scale field-aligned plasma density irregularities (striations) which requires the diagnostic radar beam to be directed orthogonal to the geomagnetic field. The striations are thought to be generated by a thermal parametric instability at the upper-hybrid resonance (UHR) height, although they extend for several tens of kilometres along the geomagnetic field (Robinson, 1989). The heater-induced scatter is very aspect-sensitive (Minkoff et al., 1974) and usually very much stronger than similarly aspect-sensitive scatter of natural origin (Dhillon et al., 2002). It is easily detected by conventional coherent backscatter radars. Many such observations of striations artificially stimulated by the EISCAT heater at Troms $\varnothing$ by the CUTLASS (Co-operative UK Twin Located Auroral Sounding System) radars have been reported (Robinson et al., 1997; Bond et al., 1997; Yeoman et al., 1997).

The second type of artificial scatter involves low frequency waves (either ion-acoustic or alternatively purely-growing mode) and high-frequency electron-acoustic waves which are thought to be driven unstable by the ponderomotive force (Fejer, 1979). These waves are excited near the reflection height of the O-mode heater wave. The scatter from these waves is less aspect sensitive than that from field-aligned striations and is typically observed by incoherent scatter radars with steerable beams, over a range of beam directions from that parallel to the geomagnetic field direction up to a few tens degrees away from it. Although, during heating experiments, the amplitudes of these waves are considerably enhanced above naturally occurring levels, the resulting backscatter is generally weaker than that of the aspectsensitive scatter from field-aligned striations. Non aspectsensitive artificial scatter has been extensively studied using both the UHF and VHF incoherent backscatter radars at 
Troms $\varnothing$ in conjunction with the EISCAT heater (Isham et al., 1990; Kohl et al., 1993; Rietveld et al., 2000).

It is known that there is a strong relationship between the evolution of the aspect-sensitive and non aspect-sensitive backscatter described above. In particular, the so-called "overshoot" phenomenon (Robinson, 1989) regularly seen in non aspect-sensitive scatter is thought to be due to the anomalous absorption (Robinson, 2002) of heater wave power at the UHR due to the relatively slow development of striations there. This quenches the more rapidly developing non aspect-sensitive scatter at the heater reflection height, which is typically a few kilometres above the UHR. Furthermore, Dhillon and Robinson (2005) have found evidence that the striations may act as waveguides for the smaller wavelength plasma waves involved in non aspectsensitive backscattering and thus affect their propagation and backscattering properties.

In spite of this physical link, there have been rather few published examples simultaneous observations of the two types of scatter, in comparison to the wealth of observations of one type or the other. Until recently, the only site where these two types of observation could be carried out routinely has been at Troms $\varnothing$, where both coherent and incoherent scatter access to the heated volume is available. However, in April 2004 a new high-power HF facility began operations on the island of Spitzbergen in the Svalbard archipelago. This new SPEAR (Space Plasma Exploration by Active Radar) facility, designed and built by the University of Leicester, in the UK, is intended to serve a number of scientific purposes. Its main role will be to carry out active space plasma experiments in the polar ionosphere and magnetosphere by exciting striations that can be used as targets for coherent scatter radar observation of otherwise unobservable dynamical processes (Yeoman et al., 1997), by stimulating Alfvén wave resonances in the magnetosphere (Robinson et al., 2000; Wright et al., 2000) and, in addition, it will also be able to function as a radar, by itself receiving backscatter from the ionosphere (low-power mode), in a manner similar to the CUTLASS radars, and possibly also from the magnetosphere (high-power mode).

The experiments reported below were mainly designed to test the capabilities of the SPEAR high-power HF beam and in particular to study the excitation of field-aligned striations. The SPEAR site is both geographically further north than that of the Troms $\varnothing$ heater and also has a higher dip angle. It is known that the three important directions in the geometry of heating experiments are determined by the normal to the ionospheric layers (which is close to the local vertical direction), the dip angle and the heater beam direction. The SPEAR geometry differs in several respects from that at Troms $\varnothing$. For example, the SPEAR beam half-power halfwidth of around $10.5^{\circ}$ in the magnetic meridian is larger than the local dip angle (around $8.5^{\circ}$ ) and for both vertical pointing and field-aligned pointing the beam will contain the spitze angle, whereas at Troms $\varnothing$ the beam is narrower and the dip angle is $12^{\circ}$. Rietveld et al. (2003) have demonstrated that this geometry has a significant influence on the response of the ionosphere to HF heating. Moreover, the EISCAT Svalbard radar operates at a frequency of $500 \mathrm{MHz}$, which is intermediate between the $224 \mathrm{MHz}$ VHF and $930 \mathrm{MHz}$ UHF EISCAT radars at Troms $\varnothing$. It is known that Landau damping, which is highly wavelength dependent, plays an important role in determining the spectral content of non aspectsensitive scatter during heating. Furthermore, SPEAR is located in the polar cap, while Tromsø is regarded as usually being within the auroral zone. The state of the ionosphere in the polar cap is much less well-known and generally different from that further south, over Troms $\varnothing$. It is thus important to compare and contrast the results of heating with SPEAR and with the Troms $\varnothing$ facility, not only for practical operational considerations, but also to shed new light on heating phenomena, which are still not well understood and which are amenable to study through varying the geometry of the heating experiment.

The present paper is intended to serve several purposes. First to provide a description of the new SPEAR facility, then to report the results of new experiments which demonstrate SPEAR's capabilities in generating enhanced backscatter phenomena and also to discuss these results, albeit briefly, in the light of what has been previously observed, particularly at the Troms $\varnothing$ heating facility. The paper is set out as follows. The new SPEAR facility is described in Sect. 2 and the arrangement of the experiment in relation to the diagnostics involved, i.e. the CUTLASS and ESR radars, is described in Sect. 3. The results of the first SPEAR observations of enhanced ESR backscatter and enhanced CUTLASS backscatter from two campaigns run in April/May and September/October, 2004 are reported in Sect. 4. The new results are discussed in Sect. 5 .

\section{The SPEAR system}

SPEAR (Space Plasma Exploration by Active Radar) is a new high-power radar system located at Lat. $78.15^{\circ} \mathrm{N}$, Long. $16.05^{\circ} \mathrm{E}$, in the vicinity of Longyearbyen (Spitzbergen) and is designed to carry out a range of space plasma investigations of the polar ionosphere and magnetosphere. The SPEAR site is located adjacent to the EISCAT Svalbard Radar (ESR) at an altitude of $420 \mathrm{~m}$ above sea-level, on a plateau on Mine 7 mountain some $10 \mathrm{~km}$ from Longyearbyen (see Fig. 1).

The SPEAR antenna system (Fig. 2). comprises a $6 \times 4$ array of full-wave, crossed-dipoles, $16 \mathrm{~m}$ above the ground, with an antenna spacing of $48.4 \mathrm{~m}$, allowing the transmission of both linear and circularly polarised signals. The individual dipoles are rhombically broadened to allow operation between 4 and $6 \mathrm{MHz}$. The site is large enough to accommodate a planned extension of the system up to a $6 \times 6$ array.

The resulting beam has a quasi-elliptical cross-section, with an average half-power width of $21^{\circ}$ along its major axis (parallel to the array north direction, shown in Fig. 2) and $14^{\circ}$ along its minor axis. This results in an overall antenna gain of $21 \mathrm{~dB}$. Individual phase-control provides beam-steering 


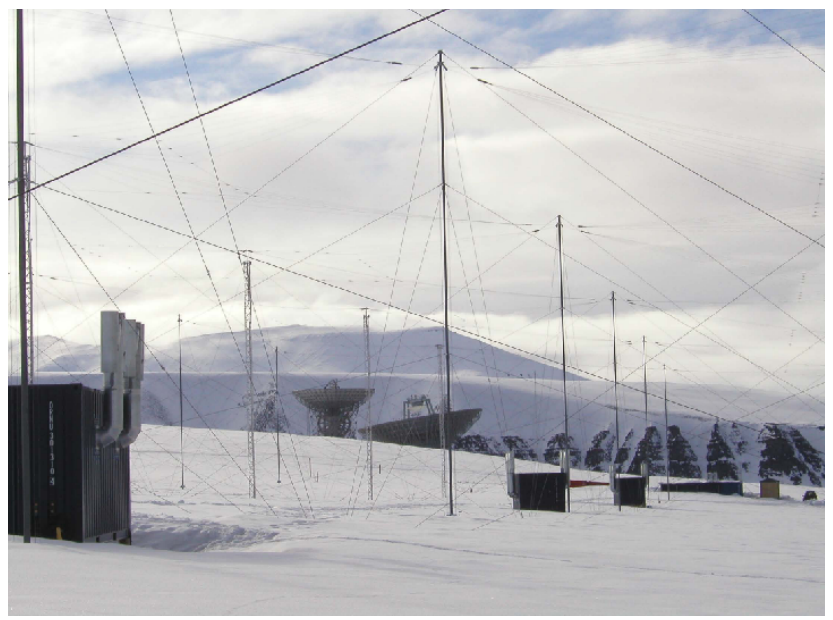

Fig. 1. A view of part of the SPEAR antenna array on mine 7 mountain, with the ESR dishes in the background.

within $\pm 30^{\circ}$ from zenith, at any azimuth, without significantly altering the antenna gain or introducing significant side-lobe signals. The beam may thus be pointed in directions which include vertical and field-aligned. Beam-steering to angles further from the zenith may be achieved but in this case significant side-lobes are introduced into the fieldpattern. A block diagram of the whole system, which interfaces to the antennas, is illustrated in Fig. 3.

SPEAR is a distributed transmitting and receiving system consisting of individual 4-kW solid-state transmitters connected to the antenna array. Each transmitter consists of a single driver-stage and 4 individual 1-kW modules, the outputs of which are combined and fed to the antenna. In the $4 \times 6$ configuration 48 such transmitters are required. These are made up of 192 power-amplifier modules, 48 driverstages and a total of 240 power-supply units. Each transmitter contains an embedded controller and an individual Direct Digital Synthesiser (DDS) which provides a transmit signal and the IF for the receiver front-end. Eight transmitters are housed in a half-sized shipping container which feeds a $2 \times 2$ sub-array. The entire SPEAR system is housed in 6 such containers. All of the transmitters were built in the Radio and Space Plasma group's workshops in Leicester, by the group's technical staff.

The control system is housed in a further shipping container located on the edge of the antenna array and feeds common clock signals and network signals to the transmit containers via optical connections. Receiver IF signals are summed in the transmitter containers and passed via copper cables to the control cabin where they are summed and fed to a single-channel receiver, the data from which is processed by the receiver data-logger. Control of the entire system is achieved by passing instructions to the distributed-system controllers within the transmitter containers. The control signal also implements safety features which prevent transmission in the presence of aircraft.

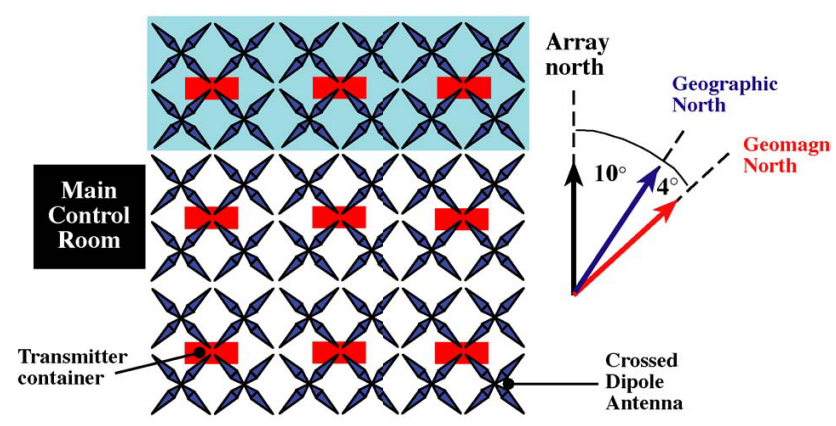

Fig. 2. Schematic of the SPEAR antenna array with transmitter containers and dipoles. The (blue) shaded area shows the planned extension. The orientation of the array is indicated by the arrows.

The transmitter containers pose a serious design constraint in that they must be both insulated and heated to allow operation with low external temperatures that are frequently below $-30^{\circ} \mathrm{C}$, but that must also be capable of dissipating some $30 \mathrm{~kW}$ of waste heat during full-power $\mathrm{CW}$ operation. This problem is compounded by the need to prevent the ingress of snow which places serious constraints on forced air cooling systems. Closed circuit cooling (air conditioning) is not appropriate due to cost considerations, high maintenance requirements and reliability concerns. Each transmitter container includes several heaters and cooling fans connected by $\mathrm{H}$-section ducting which are controlled by a container environmental controller which monitors internal and external temperatures to provide autonomous control of the heating and cooling. With the additional DDS control computer that is necessary to program the 8 DDS modules in each transmitter container, each transmitter container consists of a 10-node computer system.

The first 5 transmitter containers were completed during the autumn of 2002 and shipped along with the 4 control containers to Longyearbyen. These containers were transported to the SPEAR site and moved into position during the spring of 2003. At the same time the antenna system was shipped directly from the manufacturers to the site. The final transmitter container was retained at Leicester to permit software development and completion and testing of the phasing system. This delay meant that the antenna array was incomplete for the first operational tests in April/May 2004, although some successful scientific results were obtained (see Sect. 4 below). The $6 \times 4$ array was complete in time for the second campaign in September/October 2004.

\section{Experimental arrangements}

The primary aim of the first year of operations of SPEAR was to establish the capability of the high-power beam to generate artificial striations, in line with SPEAR's central scientific raison d'etre. The SPEAR site is within the fields of view of both the CUTLASS radars in Finland (Hankasalmi) and Iceland (Thykkvibær), (Fig. 4), which were operated throughout 


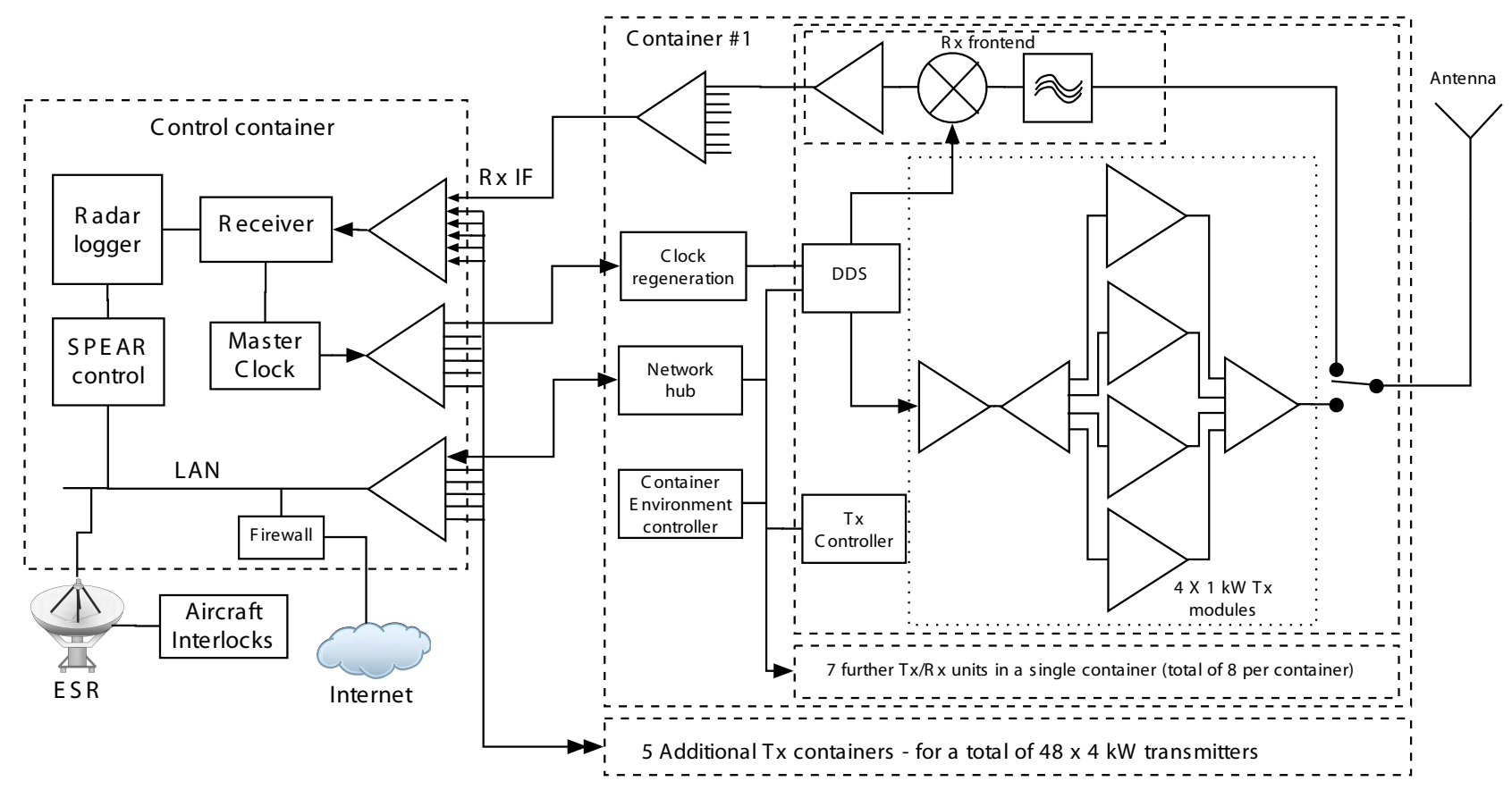

Fig. 3. A block diagram of the SPEAR system illustrating the distributed transmit and receive configuration.

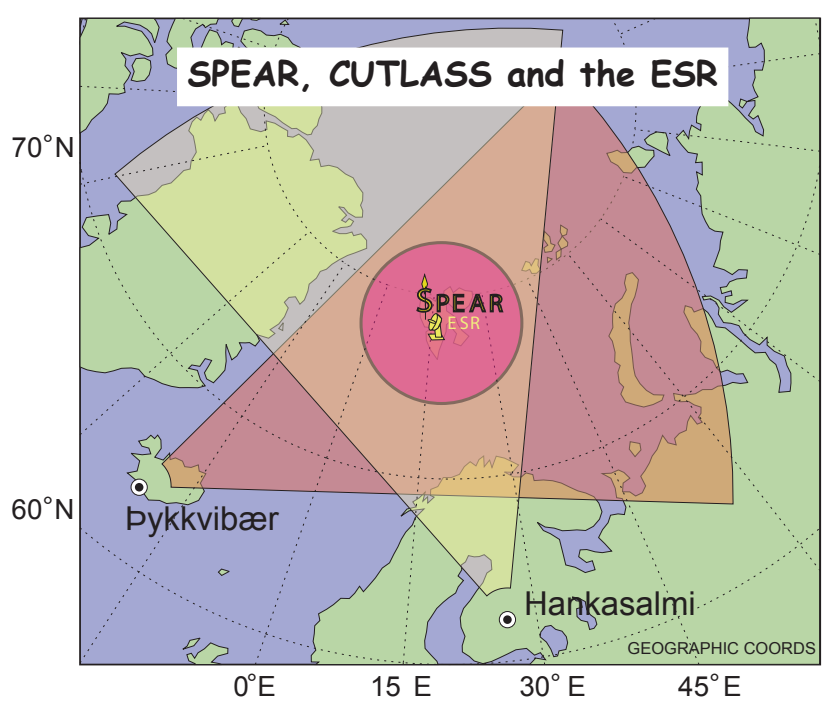

Fig. 4. Map of the locations of SPEAR, CUTLASS and ESR together with the CUTLASS Finland and Iceland radar fields of view. The pink circle represents the typical spatial coverage of ESR measurements.

the two campaigns. The ESR UHF radar was also operated, initially as a secondary diagnostic to provide information about the local background ionosphere. As it turned out, it was the ESR which provided the first evidence of SPEARinduced nonlinear effects in the ionosphere. A co-located ionosonde was also available to provide real time information about the maximum ionospheric plasma frequency. This enabled the experimenters to choose appropriate SPEAR operating frequencies.
During the April/May campaign only 35 transmitters were initially available due to the incompleteness of the system, as indicated above. These were operated a mean power of $3 \mathrm{~kW}$ and thus provided a total of $105 \mathrm{~kW}$ with an estimated antenna gain of $20 \mathrm{~dB}$. The effective radiated power in this case was just over $10 \mathrm{MW}$. However, quite soon after the beginning of the first campaign technical difficulties were encountered which resulted in the loss of transmitters. For the second campaign, the complete $6 \times 4$ array was available, i.e. 48 transmitters, which produced an antenna gain of $21 \mathrm{~dB}$. However, in view of the transmitter problems from the first campaign, it was decided to run at $2 \mathrm{~kW}$ per transmitter in the second campaign, which meant an ERP of just over $15 \mathrm{MW}$. With the experience gained from the first few campaigns, the transmitters will ultimately each be able to achieve $4 \mathrm{~kW}$, which will result in an ERP of $30 \mathrm{MW}$.

\subsection{CUTLASS operations}

The current stereo CUTLASS radar is an HF coherent backscatter radar system located at Hankasalmi, Finland and Thykkvibær, Iceland (Lester et al., 2004), capable of near simultaneous operation on two separate frequencies. The radars form part of the SuperDARN array (Greenwald et al., 1995). CUTLASS is ideally situated for making observations of the SPEAR-modified ionosphere over the ESR, since the SPEAR site is located well within the fields of view of both the CUTLASS Finland (Fig. 5a) and CUTLASS Iceland (Fig. 5b) radars. Both radars reach the ionosphere above SPEAR via a 1.5-hop HF propagation path, as shown schematically in Fig. 5c. Normal operations for both radars involve a 16-beam scan over ranges $180-3555 \mathrm{~km}$, 
(a)

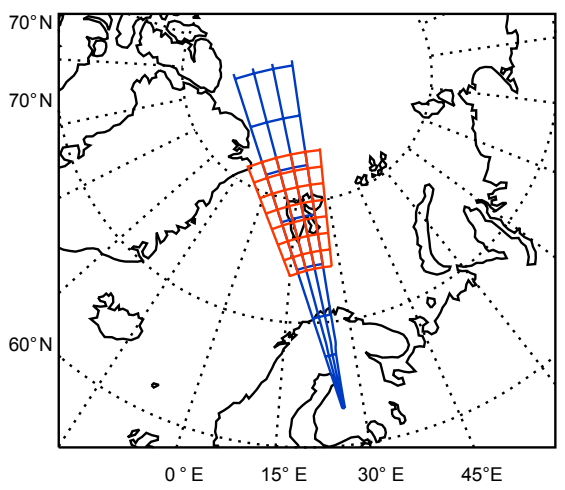

(b)

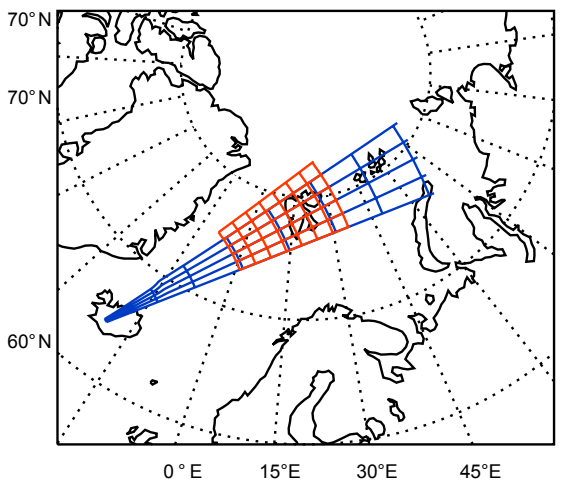

(c)

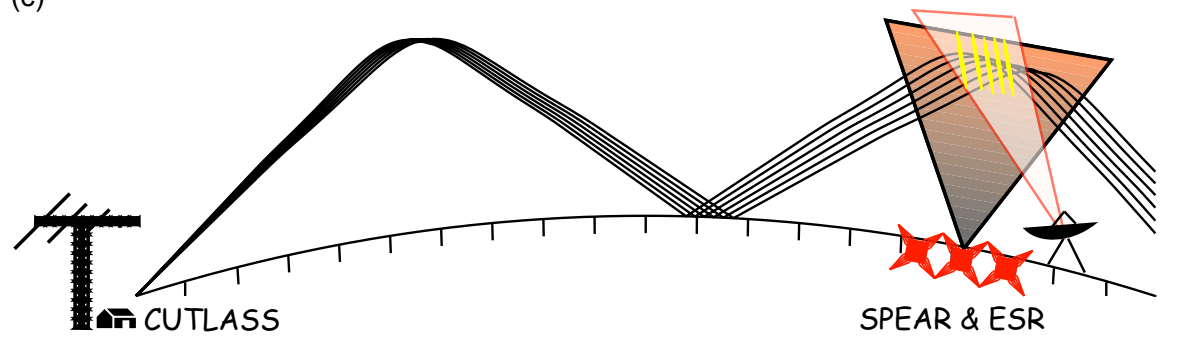

Fig. 5. Summary of CUTLASS experimental operations. (a) Scanning pattern for CUTLASS Finland, (b) scanning pattern for CUTLASS Iceland, (c) schematic of 1.5-hop propagation path between CUTLASS radar and SPEAR/ESR sites.

with an integration time of 3 or $6 \mathrm{~s}$ providing a full-scan timeresolution of 1 or $2 \mathrm{~min}$. In the experiments presented here the CUTLASS radars ran in a high temporal and spatial resolution mode, with both radars running a reduced scan of 3-5 beams centred over SPEAR (beams 6 and 9 for Thykkvibær and Hankasalmi respectively), with an integration time of $1 \mathrm{~s}$. Channel-A of each of the radars provides high spatial resolution, with a field-of-view restricted to 75 range-gates of size $15 \mathrm{~km}$ covering ranges of $1485-2610 \mathrm{~km}$, while Channel-B provides data over the complete propagation path from the HF radars to SPEAR at a resolution of $45 \mathrm{~km}$, over distances of $180-3555 \mathrm{~km}$. Both Channels-A and -B of each radar additionally perform a small frequency sweep, with the scans cycling through approximately three HF frequencies which are appropriate to allow propagation to Svalbard over a 1.5hop path. Frequencies of $11-13 \mathrm{MHz}$ were chosen for the experiments presented here. Thus the combination of the integration-time, scan-pattern and frequency-sweep provided a time-resolution of between 9 and $15 \mathrm{~s}$ in this arrangement.

\subsection{ESR operations}

The first ESR/SPEAR observations were carried out using the $32 \mathrm{~m}$ (steerable) and $42 \mathrm{~m}$ (fixed) dishes of the EISCAT Svalbard Radar. These were co-aligned in the magnetic field direction (azimuth $181^{\circ}$, elevation $81.6^{\circ}$ ), and used to record ion-line and plasma-line data respectively. The ESR experi- ment used in these observations employed the steffe modulation scheme, which uses two 16-bit alternating codes. One of these codes has a baud-length of $32 \mu$ s (total pulse-length $512 \mu \mathrm{s}$ ), while the other has a baud-length of $96 \mu \mathrm{s}$ (total pulse length $1536 \mu \mathrm{s}$ ). The former code is sampled with a fractionality of 2, and the latter code is sampled with a fractionality of 6 . This means that both codes are sampled at intervals of $16 \mu \mathrm{s}$, so that each can give a range resolution of $2.4 \mathrm{~km}$, though the data from adjacent height gates are not independent at this range resolution.

The alternating code with $16 \mu$ s baud-length yields fully decoded data between ranges of 105 and $216 \mathrm{~km}$, while the code with $96 \mu$ s baud gives fully decoded data between 259 and $924 \mathrm{~km}$. In the interval from 216 to $259 \mathrm{~km}$, spectra are derived from the alternating code with $96 \mu$ s baud, which, while not fully decoded, nonetheless provides acceptable data for most monitoring purposes. The ion-line spectra presented in this paper are shown at range resolutions of $4.8 \mathrm{~km}$ for the $16 \mu \mathrm{s}$ baud code, and $14.4 \mathrm{~km}$ for the $96 \mu \mathrm{s}$ baud code. At this range-resolution, each fully-decoded spectrum is independent of its neighbours. The frequency-resolutions for the ion-line spectra from the two alternating codes are $0.992 \mathrm{kHz}$ and $0.880 \mathrm{kHz}$.

The plasma-line data were recorded using a separate receiver chain to that used in processing the ion-line signal. Plasma-line detection is done using the power returned during a brief interval of reception from the longer of the two 


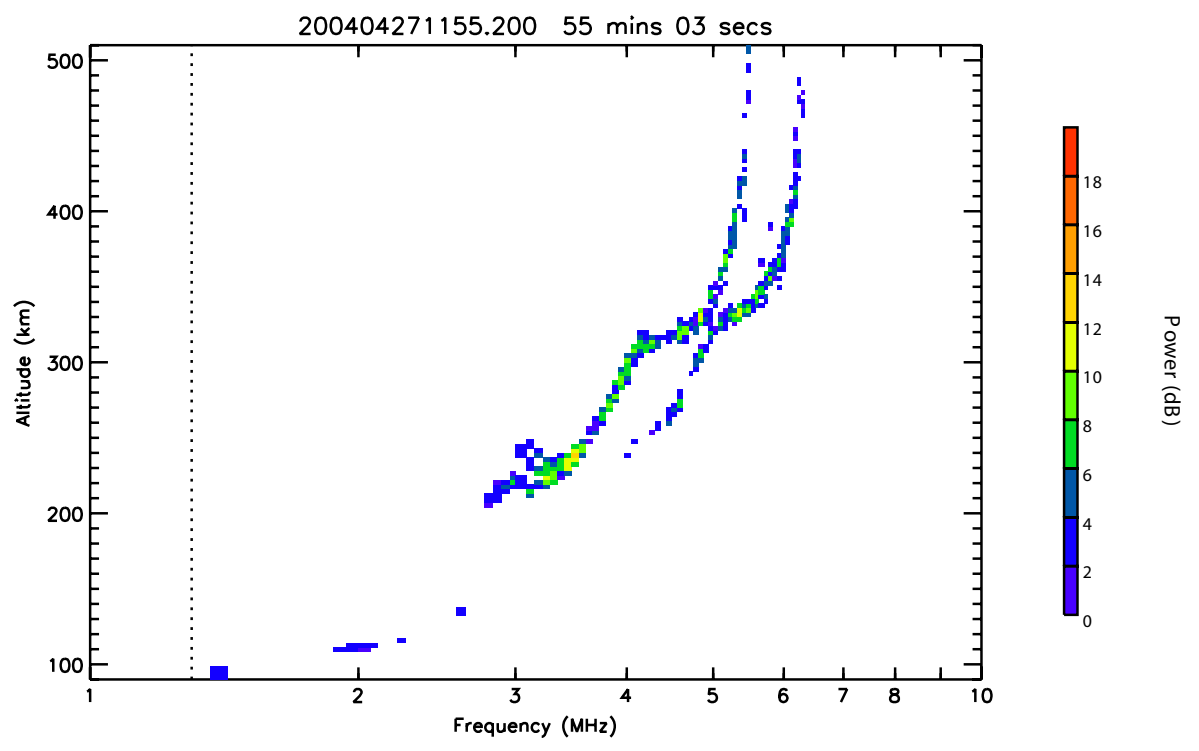

Fig. 6. Svalbard ionogram for 11:55 UT, 27 April 2004.

\section{ESR PLASMA LINE}

Plasma Line Spectral Amplitude for 27/04/2004
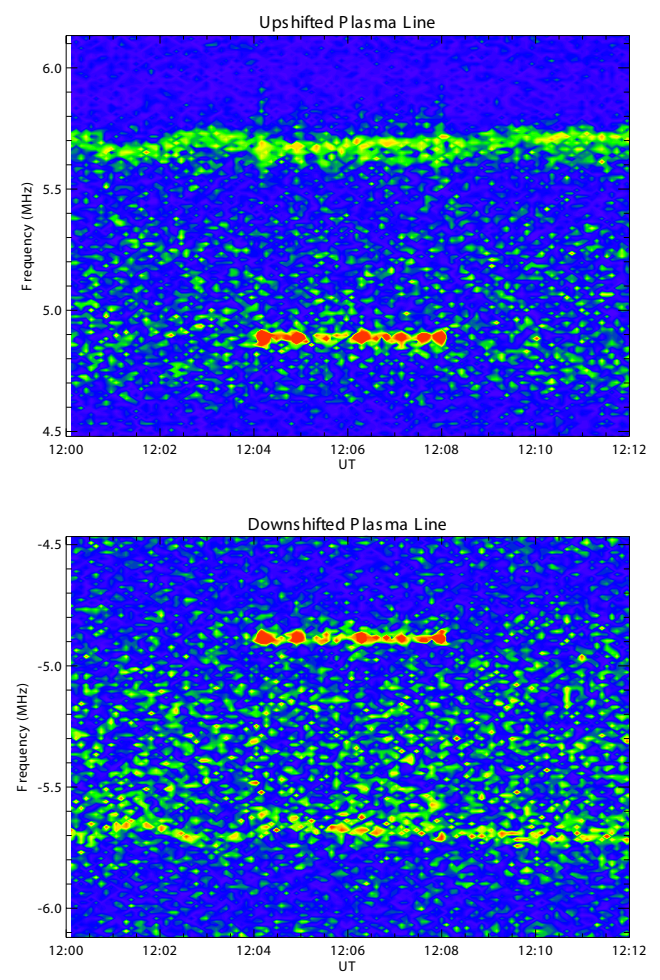

Fig. 7. ESR upshifted and downshifted plasma-line data for 12:0012:12 UT, 27 April 2004. During this period SPEAR was transmitting X-mode from 12:00-12:04 UT, O-mode from 12:04-12:08 UT and was off from 12:08-12:12 UT.

phase-coded pulses as it traverses the ionosphere, without decoding the return to enhance range resolution. As a re- sult, the data are not resolved in range, but only in frequency. The plasma-line data thus constitute two time-series of frequency-spectra, in overlapping bands of 3.2 to $4.8 \mathrm{MHz}$ and 4.5 to $6.1 \mathrm{MHz}$ (offset from the transmitted frequency), summed over all ranges from 150 to $600 \mathrm{~km}$. Within each band, the plasma-line power is divided into 128 frequencybins of width $13 \mathrm{kHz}$. The plasma-line power in most of these bins is generally small, except in regions where the gradient of the electron density profile becomes shallow (i.e. little change in electron density with increasing height). In this case, plasma-line contributions from a range of altitudes add together to create enhanced power at that particular plasma frequency. This method is sometimes referred to as the "spectral plasma-line" technique, described more fully by Showen (1979).

\section{Experimental results}

\subsection{Results from the campaign of April/May 2004}

The first attempts to observe SPEAR-induced nonlinear effects in the ionosphere above Spitzbergen commenced at 12:00 UT on 27 April 2004. SPEAR was operated at $4.9 \mathrm{MHz}$ in the following sequence: $4 \mathrm{~min}$ on in X-mode, 4 min on in O-mode, followed by 4 min off. The ERP during on periods in the first 12-min sequence was estimated at $10 \mathrm{MW}$. The SPEAR beam was directed along the geomagnetic field, as was the ESR radar. An ionogram taken at 11:55 UT (Fig. 6) indicated a maximum plasma frequency of around $5.5 \mathrm{MHz}$, so the heating was over-dense. The upshifted and downshifted plasma-line intensity spectra data from the ESR for the period from 12:00-12:12 UT, corresponding to the first 12-min sequence are illustrated in the two panels in Fig. 7. These panels show a clear intensification of the plasma-lines at $\pm 4.9 \mathrm{MHz}$ (within the frequency 


\section{ESR ION LINE}

\section{Ion Line Spectral Power for X-mode, O-mode and Heater-off for 1200-1212 UT on 27/04/2004}
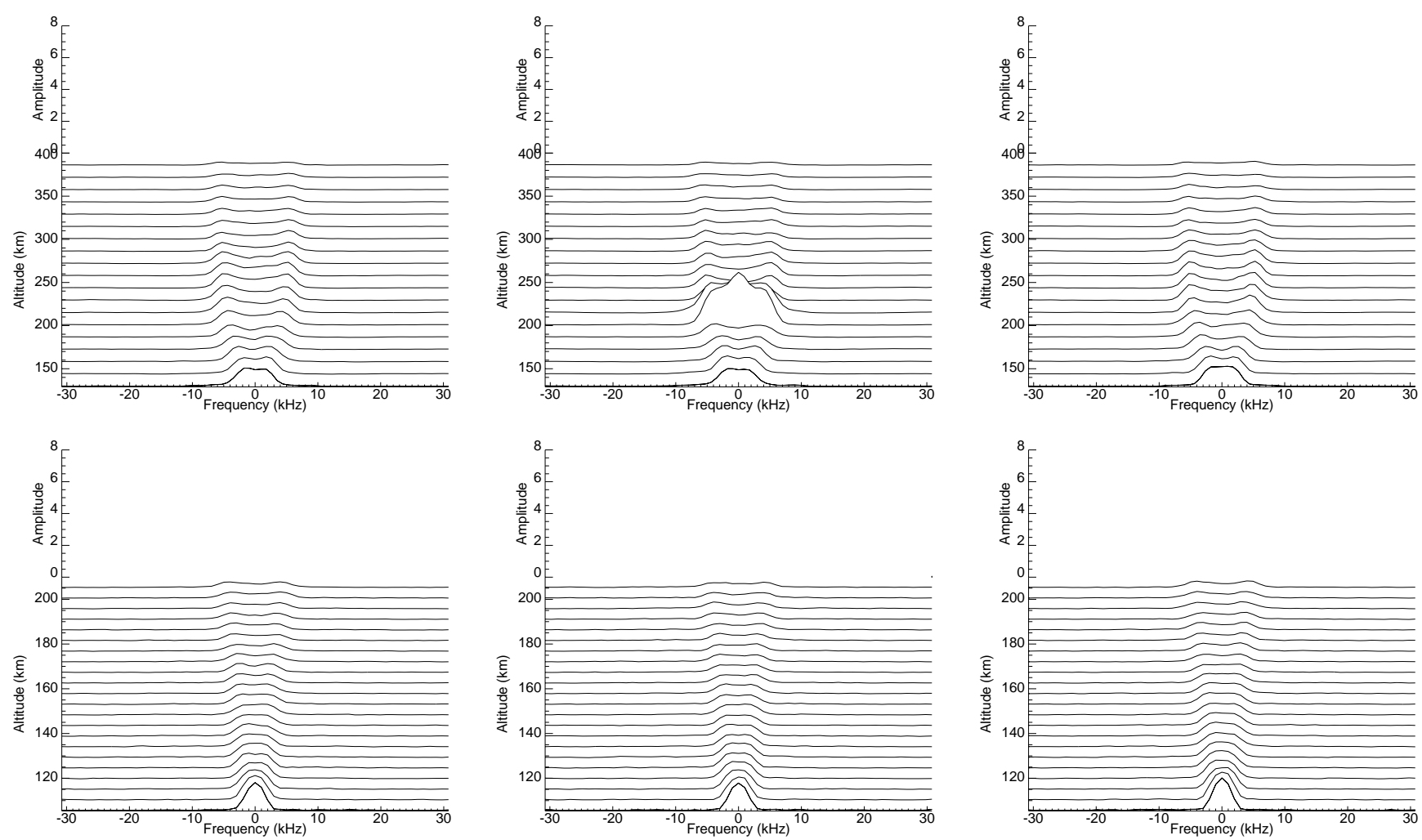

Fig. 8. ESR ion-line data for 12:00-12:12 UT, 27 April 2004. The upper panels correspond to the height range 129-757 km with a resolution of $14 \mathrm{~km}$ and the lower to $105-210 \mathrm{~km}$ with a resolution of $5 \mathrm{~km}$. The first column corresponds to SPEAR X-mode (12:00-12:04 UT), the second to O-mode (12:04-12:08 UT) and the third to off (12:08-12:12 UT).

resolution of $13 \mathrm{kHz}$ ) from the ESR transmitted frequency $(500.3 \mathrm{MHz})$ during the O-mode heating between 12:0412:08 UT. A pair of continuous weakly-enhanced natural lines (upshifted and downshifted) with a frequency varying between about $\pm 5.6-5.7 \mathrm{MHz}$ is also visible in the ESR data. These correspond to the F-region maxima in the ionospheric plasma frequency which are consistent with the ionogram data in Fig. 6. These natural lines are visible due to the limb effect caused by the lower density gradients at the peak of the ionospheric plasma density.

The corresponding ESR ion-line data are displayed in Fig. 8 . Here the data have been averaged over 4 min, corresponding to the three 4-min periods in the 12-min sequence described above. However in contrast to the plasma-line data, height information is included for the ion-line spectra. The six panels in Fig. 8 are arranged as follows. Each column includes the two overlapping height ranges described in Sect. 3.2. The altitude values along the vertical axes of the plots are the lower edge of the range bins. So whereas the $200-\mathrm{km}$ curve in the upper panel represents the range $200-214 \mathrm{~km}$, the $200-\mathrm{km}$ curve in the lower panel corresponds to $200-205 \mathrm{~km}$. Time increases along the rows from left to right. Clearly the X-mode (first column) and the off-period (last column) are virtually indistinguishable, indicating no effect of the SPEAR beam during X-mode heating. The height variation of the spectral shapes during these two periods is typical of the transition from single-humped spectra from the collisional E-region to double-humped in the F-region. However, equally clear is the strong modification of the ion spectrum for the period of O-mode heating (middle column), at a height close to $200 \mathrm{~km}$ (upper panel), which corresponds to the SPEAR-ionosphere interaction height, close to where the plasma frequency is $4.9 \mathrm{MHz}$, in this instance. The reason why there is no enhancement in the corresponding 200-km curve in the lower panel (middle column) is probably due to the interaction layer being very narrow in altitude (Djuth et al., 1994) and, in this instance, its lying close to the upper edge of the range bin in the upper panel, i.e. just below $214 \mathrm{~km}$. The upper curve in the lower panel only covers the altitude range $205-210 \mathrm{~km}$. The SPEAR-affected spectra show two clear characteristics. The spectral power is enhanced by a factor of between two and three and there is a central peak corresponding to the purelygrowing mode (Fejer and Leer, 1972). 


\section{ESR SPECTRAL DATA}

\section{$\mathrm{IL}(\mathrm{U}, \mathrm{C}$ and $\mathrm{D})$ and $\mathrm{PL}(\mathrm{U}$ and $\mathrm{D})$ on 27/04/2004}

a
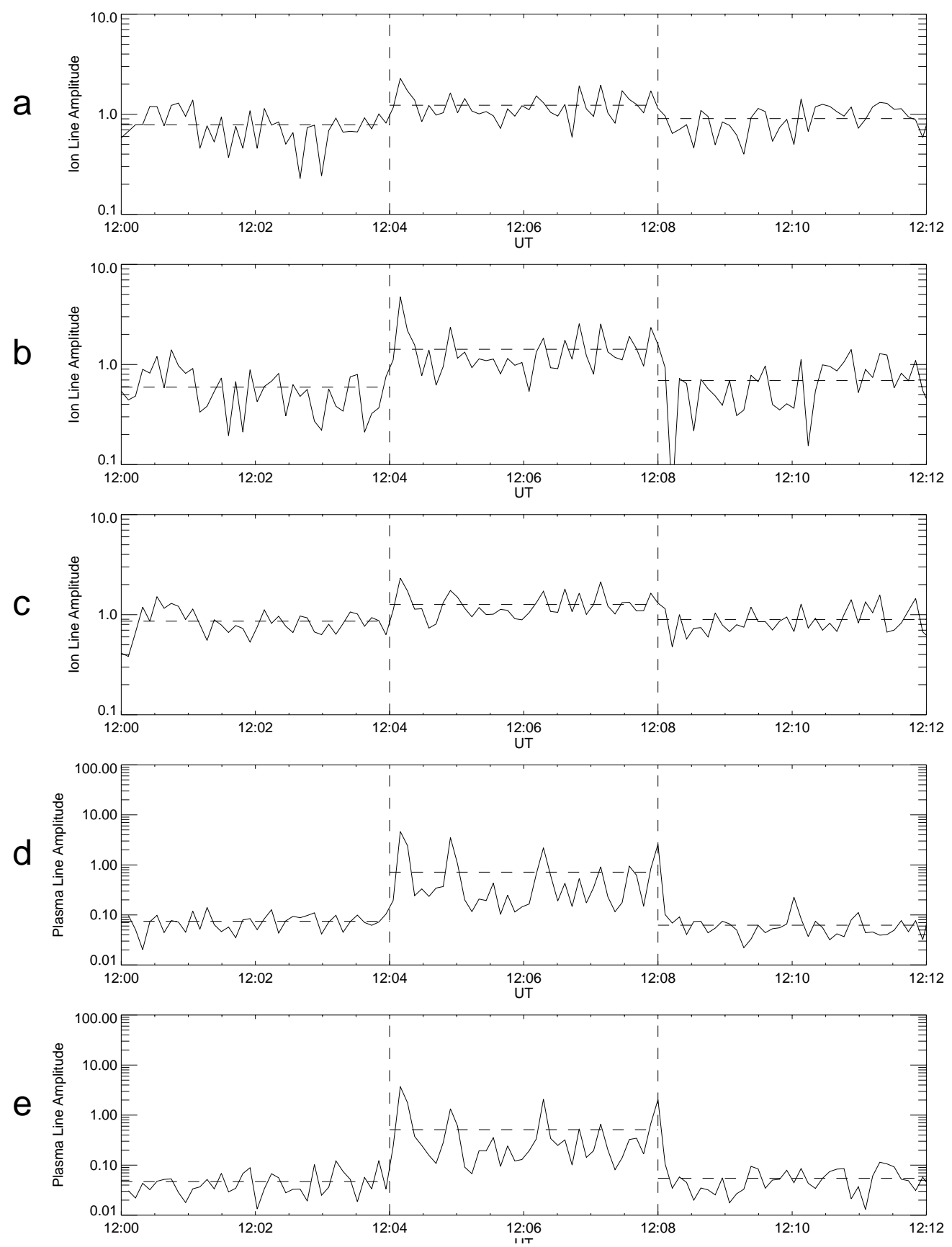

Fig. 9. Time series of amplitudes of ESR ion- and plasma-lines for 12:00-12:12 UT, 27 April 2004. Panel (a) contains the upshifted ion-line; (b), the unshifted ion-line centre frequency; (c), the down shifted ion-line; (d), the upshifted plasma-line and (e), the downshifted plasma-line.

Time-series of the amplitudes of various key components of ESR incoherent scatter spectrum are shown in Fig. 9. The upper three panels illustrate the amplitudes of three elements of the ion spectrum (upshifted ion-acoustic line, centre-frequency and downshifted ion-acoustic line respectively) and the bottom two illustrate the amplitudes of the upshifted $(+4.9 \mathrm{MHz})$ and downshifted $(-4.9 \mathrm{MHz})$ plasmalines, as functions of time from 12:00-12:12 UT. 4-min 
AVERAGED ESR ION LINE SPECTRA FROM 27/04/2004

Heater-on, 1204-1208 UT (solid), and heater-off, 1208-1212 UT (dashed), at $215 \mathrm{~km}$ altitude

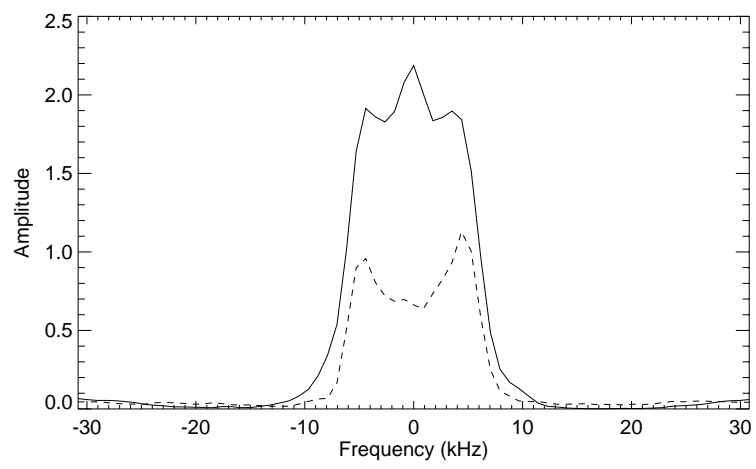

Fig. 10. Comparison of average ion spectra for SPEAR on with that for SPEAR off at 4.9 MHz for 12:04-12:12 UT, 27 April 2004.

averages are indicated by dashed horizontal lines. Significant enhancements in all these features are present throughout the SPEAR O-mode operation (12:04-12:08 UT) although the amplitudes vary considerably from dump to dump. The plasma-lines are enhanced by a factor of around ten, on average, over the natural background levels (seen during the off-period from 12:08-12:12 UT), but there are peaks of up to about a hundred times background. Also, there is a high degree of correlation in all five elements of the spectrum, as well as a high degree of symmetry between the upshifted and downshifted elements.

A more detailed comparison between the average O-mode and the average off results for the ion spectra from the period above is displayed in Fig. 10. This shows that the pair of upshifted and downshifted ion-acoustic lines have been enhanced by a factor of two, whereas the centre frequency has been enhanced by more than three times. It is also clear that the separation of the two ion-lines has not been affected by SPEAR, which probably means that there has been no significant electron temperature change during the 'heating' process. The results in Figs. 7 to 10 are consistent with the excitation of both the parametric decay instability (Fejer, 1979) and the purely-growing mode instability (Fejer and Leer, 1972) by three-wave interactions that also excite electron-acoustic (plasma) waves close to $\pm 4.9 \mathrm{MHz}$. Strictly, the parametric decay instability excites plasma-lines which are shifted from those excited by the purely-growing instability by around half the ion spectral-width, i.e., by a few $\mathrm{kHz}$. However the plasma-line spectral resolution of $13 \mathrm{kHz}$, available in the present experiments, is insufficient to resolve this separation.

Although further transmissions of the same 12-min sequences were subsequently attempted during the course of the 27 April and the next two days, similar results to those seen during 12:00-12:12 UT on 27 April were seen only spasmodically. This was partly due to deteriorating ionospheric conditions but also due to technical difficulties which led to a slowly reducing number of operating transmitters.
AVERAGED ESR ION LINE SPECTRA FROM 27/04/2004

Heater-on, 1307-1308 UT (solid), and heater-off, 1308-1309 UT (dashed), at $215 \mathrm{~km}$ altitude

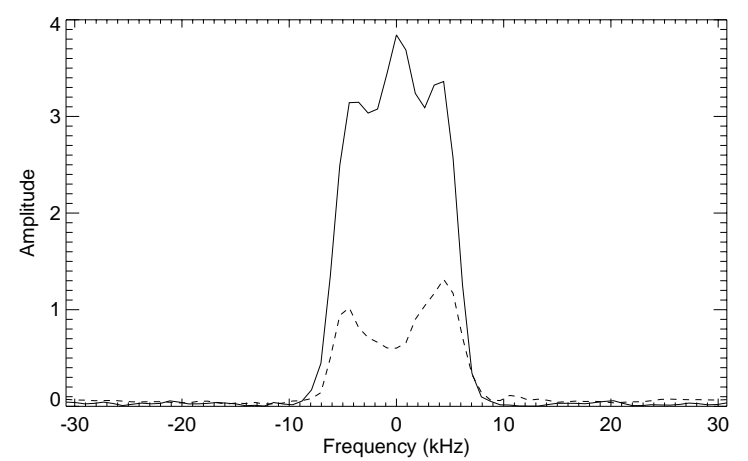

Fig. 11. As for Fig. 10, but at 5.2 MHz for 13:07-13:09 UT, 27 April 2004.

There was however a short burst of enhanced spectral power observed for a few data dumps between 13:08 and 13:09 UT on 27 April while SPEAR was operating at 5.2 MHz. The average ion spectra from the 4 min of O-mode heating and the 4 min of off are illustrated in Fig. 11. The results are similar to those in Fig. 10, but the enhancements are even greater.

The final point to make about the results from the first campaign is that no SPEAR-induced CUTLASS backscatter was seen at all. The reasons for this negative result are not entirely clear. It is possible that the beam produced by the incomplete SPEAR antenna array had an adverse effect on the production of striations, although, the positive results from the ESR show that there were no such adverse effects on the instabilities responsible for field-parallel scatter. Another possibility is that adverse propagation conditions from the CUTLASS radar sites to Svalbard were responsible for the lack of coherent scatter, although this is not at all obvious from the ionogram information taken at the time.

\subsection{Results from the campaign of September/October 2004}

In contrast to the first SPEAR campaign, for the second campaign the SPEAR $6 \times 4$ antenna-array was complete. This allowed slightly higher powers (15 MW ERP) to be used. Apart from a slightly different choice of SPEAR operating frequency, the only other differences in the way the experiments were conducted was that for the second campaign an 8-min heater sequence of 4-min on in O-mode and 4-min off was chosen. In many respects the results of ESR observations from the second campaign mirrored those of the first. A particularly strong example of the excitation of plasma-lines and ion spectral modification is illustrated in Fig. 12 (only the upshifted plasma-line is illustrated and the altitude of the strongly enhanced averaged ion-line spectrum was close to $200 \mathrm{~km}$ ) for the period from 12:46-12:54 UT on 1 October 2004. Here SPEAR was operated at $4.45 \mathrm{MHz}$ in an ionosphere with a maximum plasma frequency of $5.5 \mathrm{MHz}$. The amplitudes of five spectral elements of ESR scatter are shown in Fig. 13 for the period 12:46-12:54 on 1 October 


\section{ESR PLASMA AND ION LINES}

\section{PL Amplitude and IL Spectra for SPEAR (On and Off) 01/10/2004}
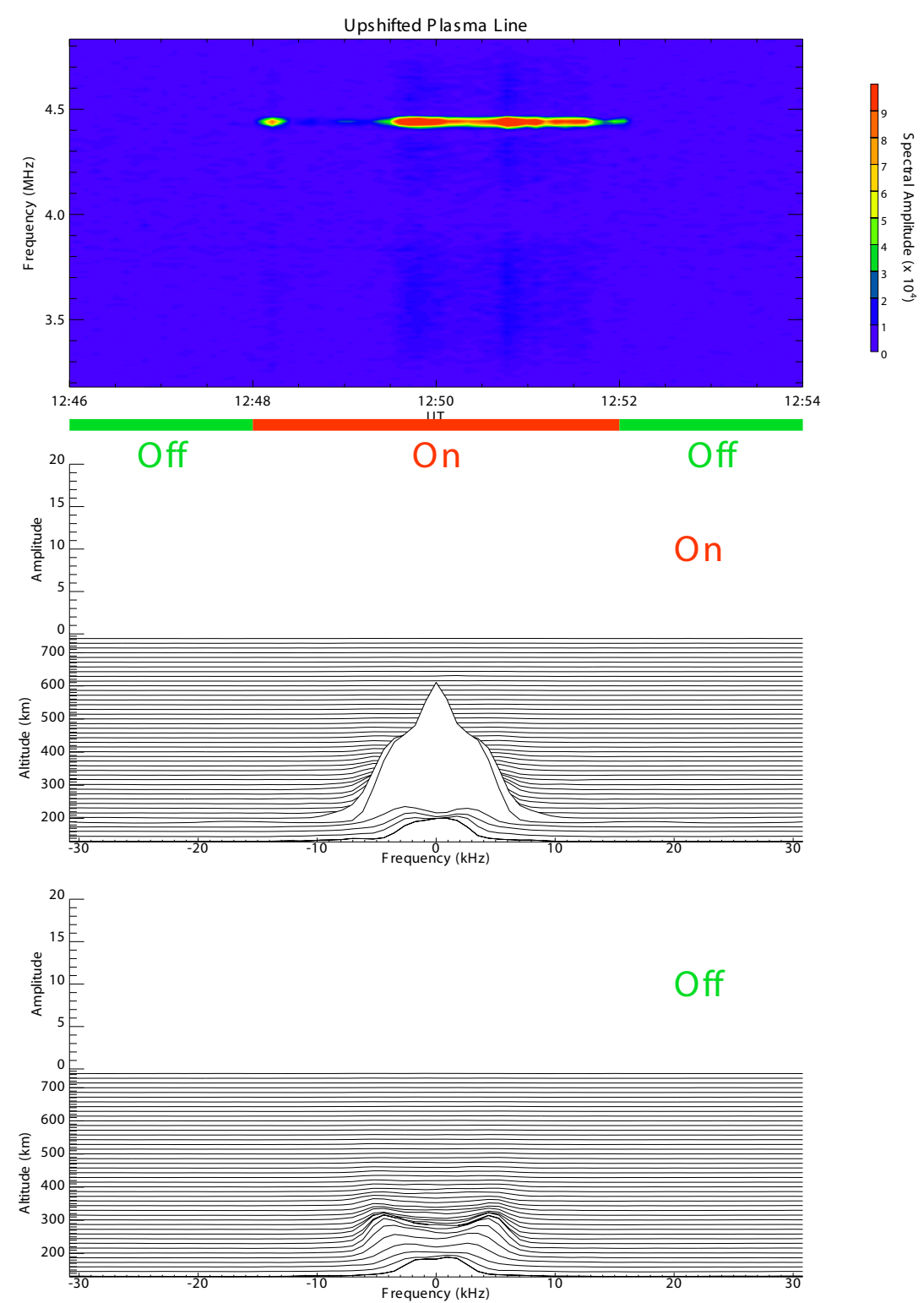

Fig. 12. ESR plasma-line is shown in the upper panel during 12:46-12:54 UT 1 October 2004, together with the average ion-line spectra for O-mode SPEAR-on (centre panel) and SPEAR-off (lower panel).

2004. Again highly variable but sustained enhancements are clear in all of the spectral features during O-mode heating. Also there is a high degree of correlation in all of the five elements as well as a high degree of symmetry between the upshifted and down shifted elements. Although during this particular period of heating, as throughout the first campaign, no SPEAR-induced CUTLASS backscatter was observed, it was observed for the first time during this second campaign.
Figure 14 illustrates the first distinct observation of SPEAR-induced CUTLASS backscatter from artificial fieldaligned striations. A sequence of three 4-min periods of O-mode heating (separated by 4-min off-periods) at times between 13:15-13:45 UT on 28 September 2004, is included, while SPEAR was operating at $4.6 \mathrm{MHz}$. Clear artificial backscatter power signatures from channelA of the CUTLASS Finland radar, at frequencies between 


\section{ESR SPECTRAL DATA}

\section{$\mathrm{IL}(\mathrm{U}, \mathrm{C}$ and $\mathrm{D})$ and $\mathrm{PL}(\mathrm{U}$ and $\mathrm{D})$ on $01 / 10 / 2004$}
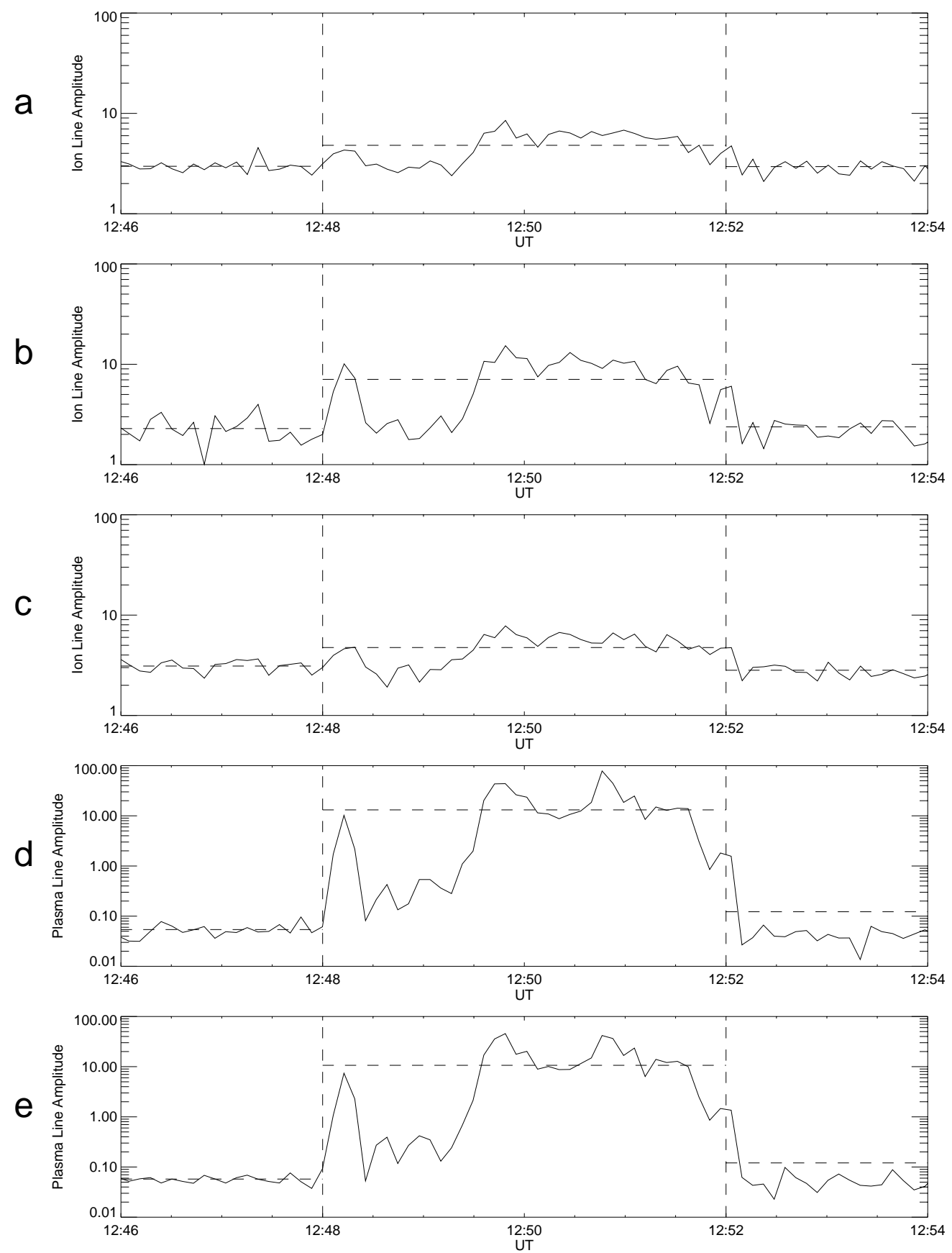

Fig. 13. Time series of amplitudes of ESR ion- and plasma-lines for 12:46-12:54 UT, 1 October 2004. Panel (a) contains the upshifted ion-line; (b), the unshifted ion-line centre frequency; (c), the down shifted ion-line; (d), the upshifted plasma-line and (e), the downshifted plasma-line.

11.075-11.275 MHz, can be seen between range-gates 41 to 50 during the first three transmission periods. The range resolution was $15 \mathrm{~km}$. The actual location of the backscat- ter is somewhat difficult to determine precisely, due to the long ranges involved. The CUTLASS Finland radar is located at a ground range of $1800 \mathrm{~km}$ from the SPEAR site. 


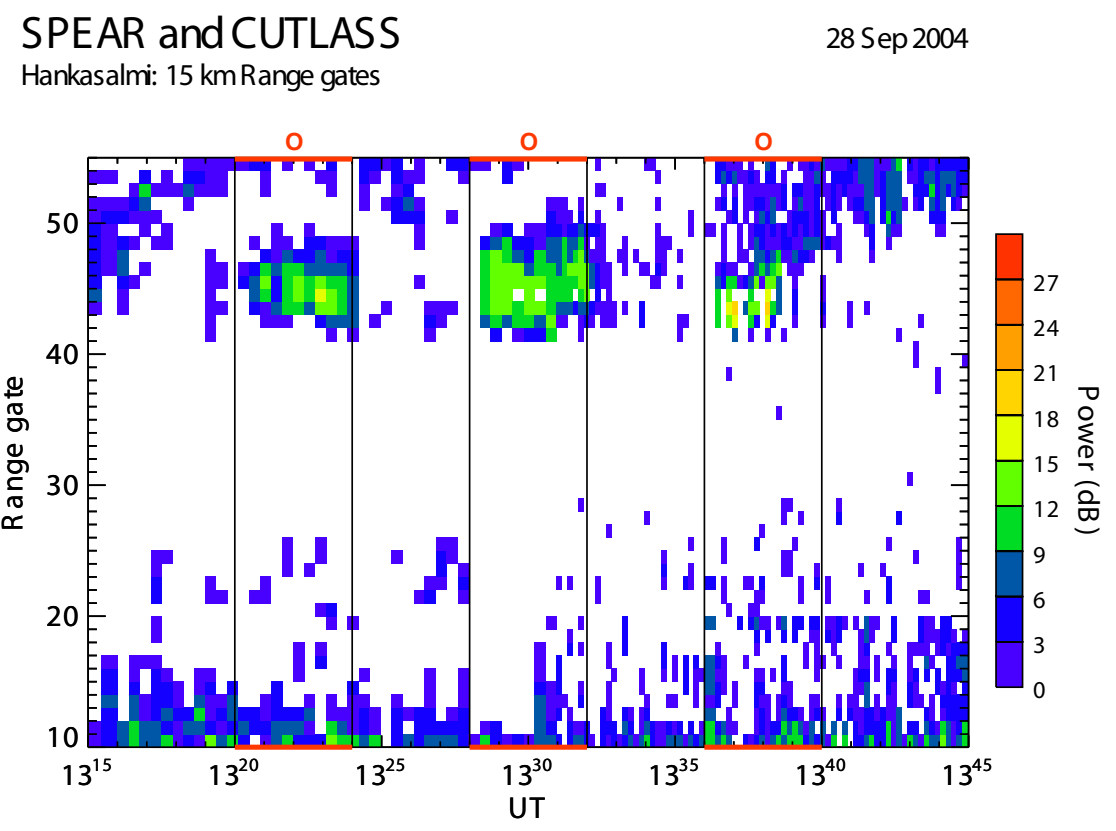

Fig. 14. CUTLASS Finland radar range time amplitude plot showing the first observation of SPEAR induced scatter, 13:15-13:45 UT, 28 September 2004.

The long ranges involved, and the over-the-horizon propagation path, mean that the time-of-flight information is not sufficient to obtain the exact ground range of the backscatter over SPEAR. The fact that the CUTLASS signal can only reach SPEAR by reflection from both the sea surface and the ionosphere (see Fig. 5) also adds to the uncertainty. Despite these complications, the group-propagation range was found to be approximately $230 \mathrm{~km}$ longer than that predicted by straight line propagation from CUTLASS Finland to an altitude $200 \mathrm{~km}$ directly above SPEAR. The continuous scatter in the very near ranges in Fig. 14 is natural ground scatter. The CUTLASS Iceland radar was not operating during this period, due to power line maintenance that lasted from 10:00-17:00 UT on 28 September 2004.

During the sequences illustrated in Fig. 14, enhancements in the ESR plasma-line and ion spectral power were also observed in addition to the CUTLASS backscatter above. Time-series of the CUTLASS backscatter power (averaged over the heated patch) for channel-A, together with those for the five elements of the ESR backscatter data (as in Figs. 9 and 13) are shown in Fig. 15 for the period from 13:20 to 13:40 UT on 28 September 2004. Three periods of O-mode heating (13:20-13:24, 13:28-13:32 and 13:36-13:40 UT) are illustrated, separated by 4-min periods when SPEAR was off.

SPEAR-enhanced CUTLASS (Finland) backscatter well in excess of $10 \mathrm{~dB}$ above background is evident in Fig. 15. All of the ESR spectral features also exhibit enhancement to some degree during SPEAR heating, though the variability in amplitude is greater than that in the corresponding CUTLASS data (except during 13:36-13:40 UT). The enhancements in the ion-line spectra in Fig. 15 appear somewhat smaller than in previous examples above (apart from a large spike just after 13:31 UT), although the upshifted artificial plasma-line (panel e) is strongly enhanced. There is also substantially more asymmetry between the upshifted and downshifted plasma-line responses in this example than in others presented previously. These differences from previous examples may have been due to ionospheric conditions as evinced by the ionogram in Fig. 16 for 13:26 UT on 28 September 2004, which was taken during a SPEAR-off period. This ionogram exhibits significant spreading, which is indicative of patchy and uneven plasma densities, even though the maximum plasma frequency appears to be above the transmission frequency of SPEAR.

An example of a period of heating when SPEAR-induced backscatter was observed in both the Iceland and Finland CUTLASS radars is illustrated in the amplitude time-series in Fig. 17. The upper two panels show the Finland and Iceland backscatter data, respectively, and the bottom five panels contain the five ESR spectra similar to those in Figs. 9, 13 and 15, but here for 13:12-13:40 UT on 1 October 2004, while SPEAR was operating at $4.45 \mathrm{MHz}$. The CUTLASS Finland data has $15 \mathrm{~km}$ range-resolution and $20 \mathrm{~s}$ time-resolution at frequencies between $11.075-11.275 \mathrm{MHz}$, while the Iceland data has $45 \mathrm{~km}$ range-resolution and $36 \mathrm{~s}$ time-resolution at frequencies between 12.6 to $13.3 \mathrm{MHz}$. The differences in these aspects of the two CUTLASS data sets are due to the fact that the artificial scatter was only clearly seen in each radar with the different modes that were described in Sect. 3.1 above. Ionospheric conditions were considerably more stable during this period, than they were for the results in Fig. 15, as is illustrated by the ionogram data from 13:18 UT on 1 October 2004 (Fig. 18). Strong backscatter is seen in both of the CUTLASS radar 


\section{CUTLASS AND ESR BACKSCATTER DATA}

$\mathrm{BP}, \mathrm{IL}(\mathrm{U}, \mathrm{C}$ and $\mathrm{D})$ and $\mathrm{PL}(\mathrm{U}$ and $\mathrm{D})$ on 28/09/2004

a
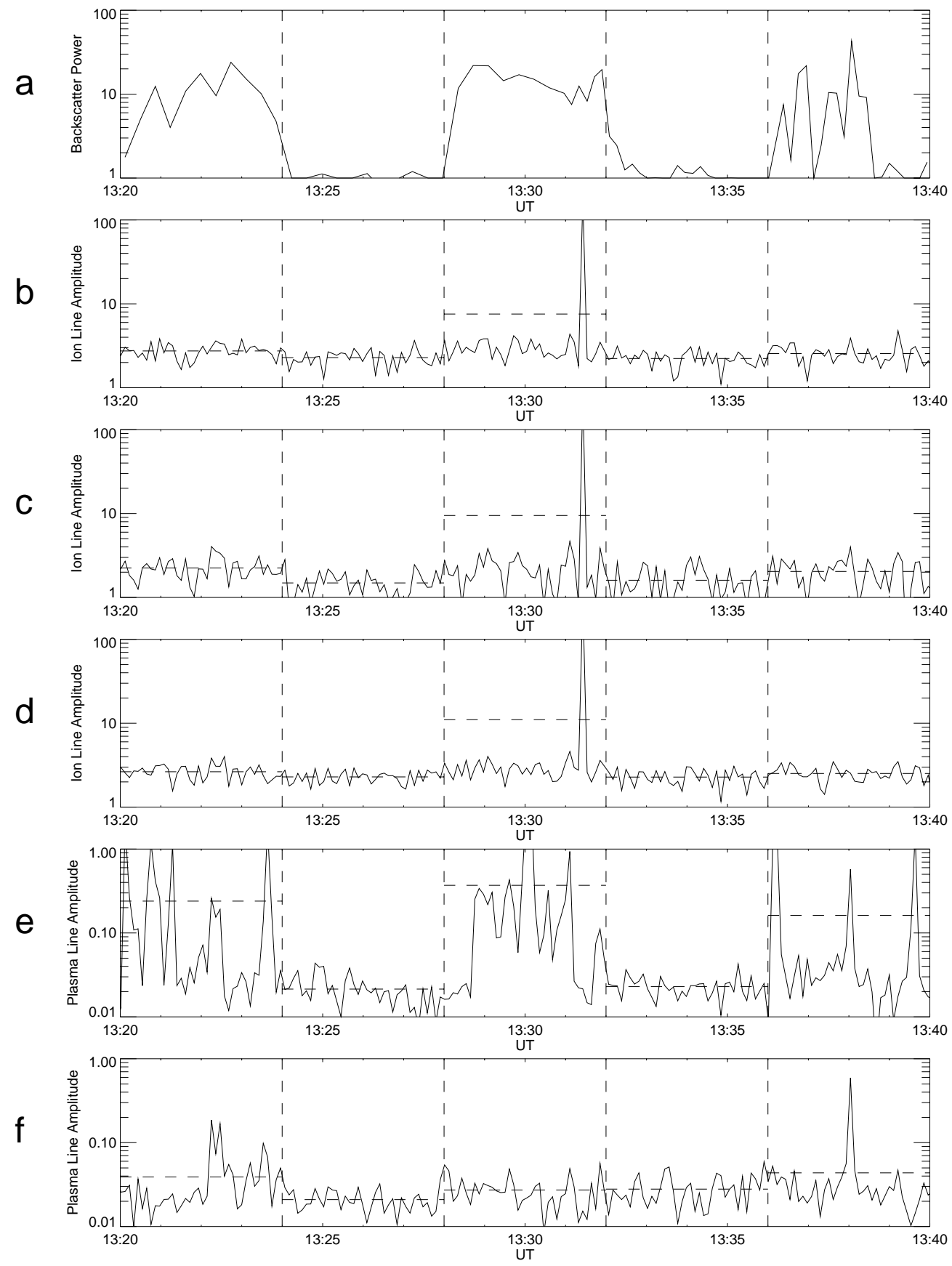

Fig. 15. Time series of amplitudes of CUTLASS Finland backscatter power (panel a), together with ESR ion- and plasma-lines for 13:20 13:40 UT, 28 September 2004. Panel (b) contains the upshifted ion-line; (c), the unshifted ion-line centre frequency; (d), the down shifted ion-line; (e), the upshifted plasma-line and (f), the downshifted plasma-line.

data sets, during three periods of O-mode SPEAR heating (13:12-13:16, 13:20-13:24 and 13:28-13:32 UT). The amplitudes seen from Iceland are somewhat larger than those from Finland, which is rather puzzling, given that the ground ranges of two radars from SPEAR are similar (Finland is at $1800 \mathrm{~km}$ and Iceland is at $2018 \mathrm{~km}$ ). This result may partly 


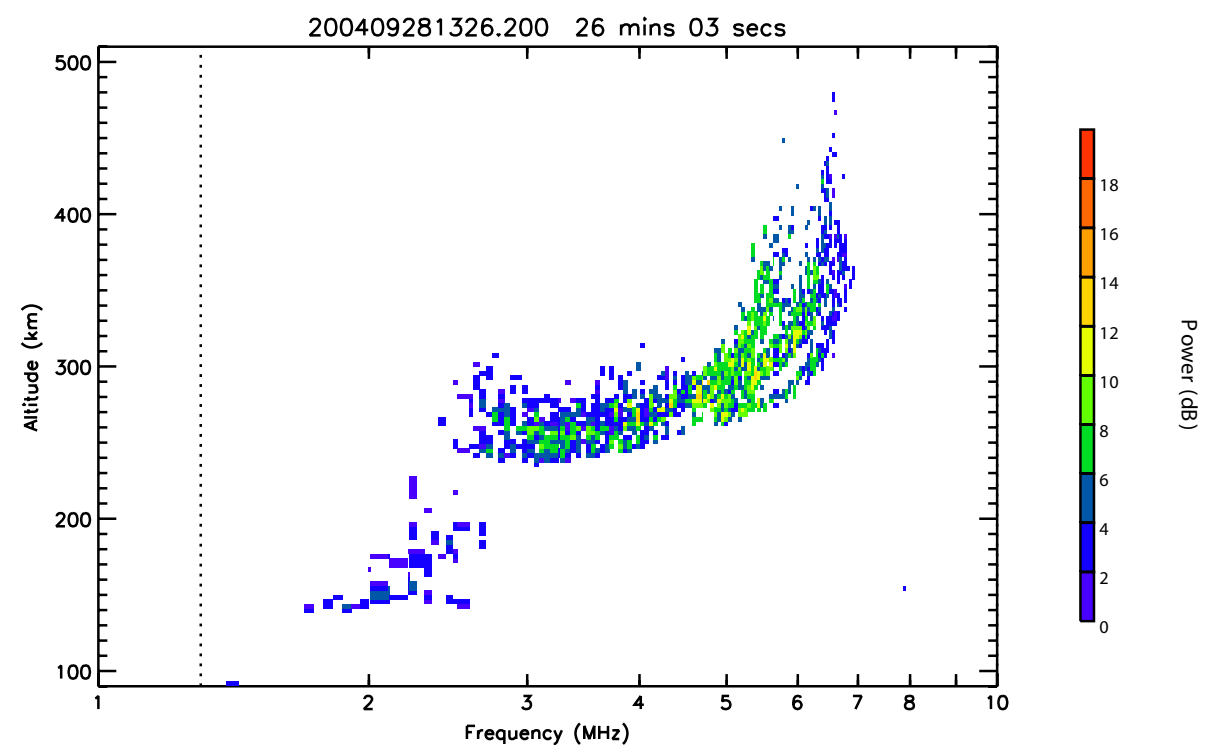

Fig. 16. Svalbard ionogram for 13:26 UT, 28 September 2004.

be explained by the range cells for the Iceland radar being three times longer than those at Finland. This increases the volume of scatter and hence the effective scattering crosssection by the same factor, assuming the scattering crosssection to be homogeneous in range within a range-beam cell and the heated patch occupies several consecutive range gates (which it clearly does from Fig. 14). Artificial striations are known to occupy a limited height range (Robinson, 1989) and so do not fill the radar beams as far as elevation is concerned. The vertical extent of the scatter is also limited by aspect-sensitivity and refraction effects. However, the heating patch is wide enough to fill the CUTLASS beams as far as azimuth is concerned. This implies that the backscatter power should fall approximately at a rate inversely proportional to the third power of the range. On this basis it might be expected that the Iceland backscatter power be reduced by $30 \%$ over the Finland backscatter power due to the $10 \%$ increase in range from SPEAR. This suggests the Iceland power should be about twice those of Finland. The peak values seen at Iceland certainly exceed those at Finland by more than this factor. This discrepancy probably deserves further investigation. However, absolute comparisons of powers from two different radars are complicated by propagation, especially with 1.5-hop modes over such large ranges, as well as the uncertainties introduced by aspect-angle considerations.

Also in Fig. 17, all the ESR spectral powers show strong enhancements during the O-mode heating, although there is huge variability, especially in the period from 13:1213:16 UT, where an intense enhancement appears for about 1 min after 13:14 UT. This enhancement also appears to coincide with the rise of backscatter power in the CUTLASS Iceland data, though the corresponding Finland data appear more uniform in time. There is generally good correlation of the 4-min averaged data (corresponding to either SPEAR- on or SPEAR-off periods) for all of the seven time-series in Fig. 17, though the ESR data are in general more variable on shorter time-scales.

\section{Discussion and conclusions}

The data presented above show clearly that the new SPEAR facility is capable of generating enhancements in fieldaligned plasma density striations that produce artificial aspect-sensitive scatter in the CUTLASS radars and also of generating enhancements in ion-acoustic waves, purelygrowing (ion) modes and electron-acoustic waves which give rise to enhanced ESR scatter. Since one of the main purposes of SPEAR is to create artificial scatter for purposes of geophysical space plasma exploration with CUTLASS, it is useful to compare the efficiency of SPEAR with that of the Troms $\emptyset$ heater, with the proviso already mentioned concerning direct comparisons between results from different sites.

As has been pointed out already, the SPEAR heater has operated so far only at ERP levels of $15 \mathrm{MW}$, while the Troms $\varnothing$ heater is capable of $200 \mathrm{MW}$ or more. An example of CUTLASS (Finland) backscatter measurements at Troms $\varnothing$ on one of the few occasions when the heater there was operating at powers considerably less than this is illustrated in Fig. 19 for 12:20-12:40 UT on 7 October 1997. Even this experiment was not ideal for comparison with SPEAR, due to the nature of some of the heater-on periods, as described below.

The lower panel in Fig. 19 indicates the ERP level of the Troms $\emptyset$ heater. As is clear, the heater-on from 12:2112:22 UT was at a constant power level, as was each subsequent alternate heater-on. In between the constant power heater-on periods were interspersed more complicated power variations, which involved the heater being on initially at full-power for $20 \mathrm{~s}$, before reverting to a lower power for 


\section{CUTLASS AND ESR BACKSCATTER DATA}

$\mathrm{BP}(\mathrm{F}$ and $\mathrm{I}), \mathrm{IL}(\mathrm{U}, \mathrm{C}$ and $\mathrm{D})$ and $\mathrm{PL}(\mathrm{U}$ and $\mathrm{D})$ on 01/10/2004

a

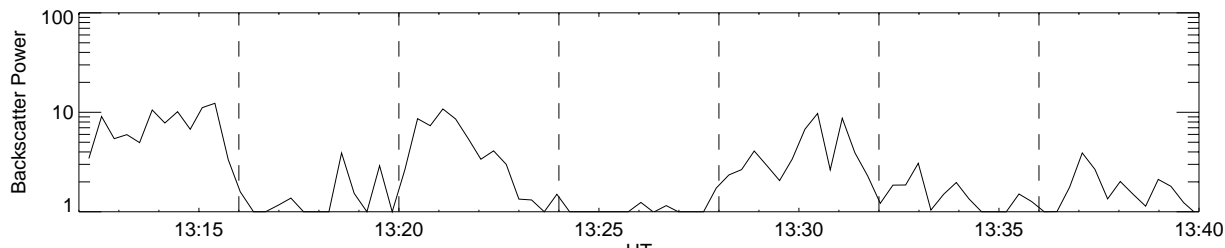

b

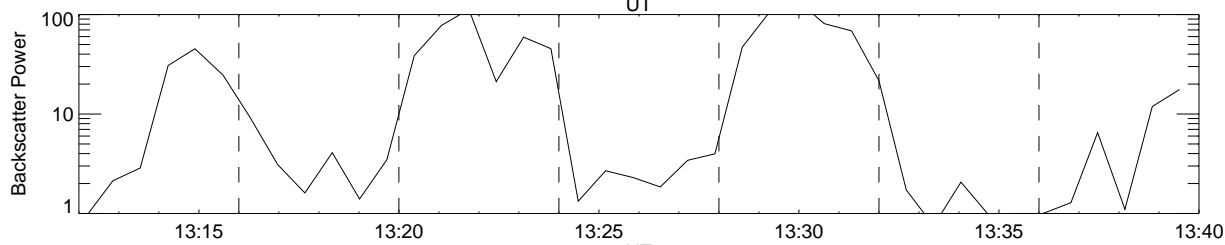

C
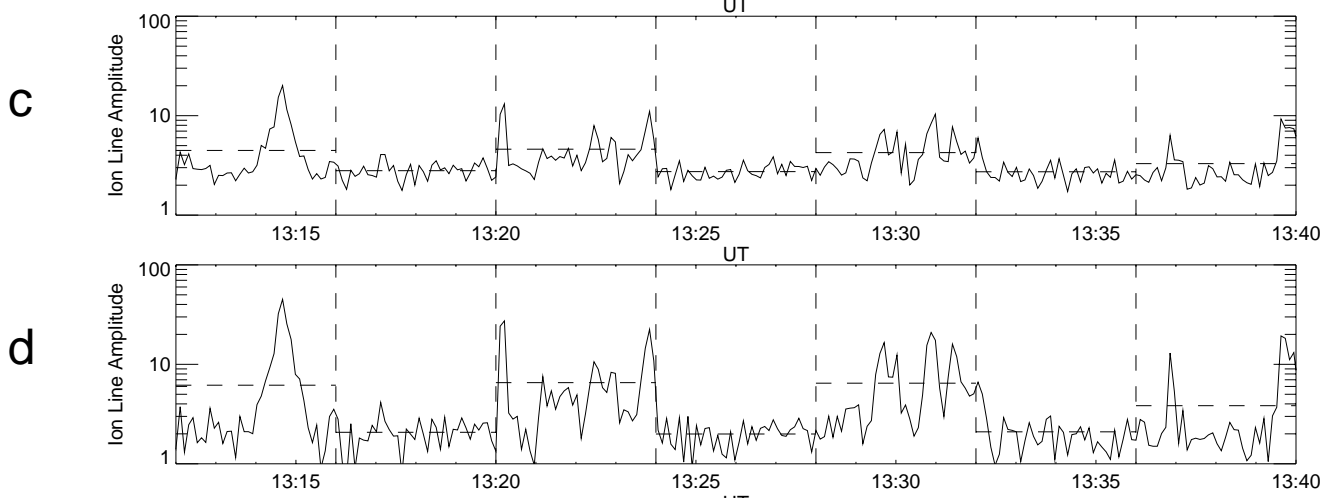

e
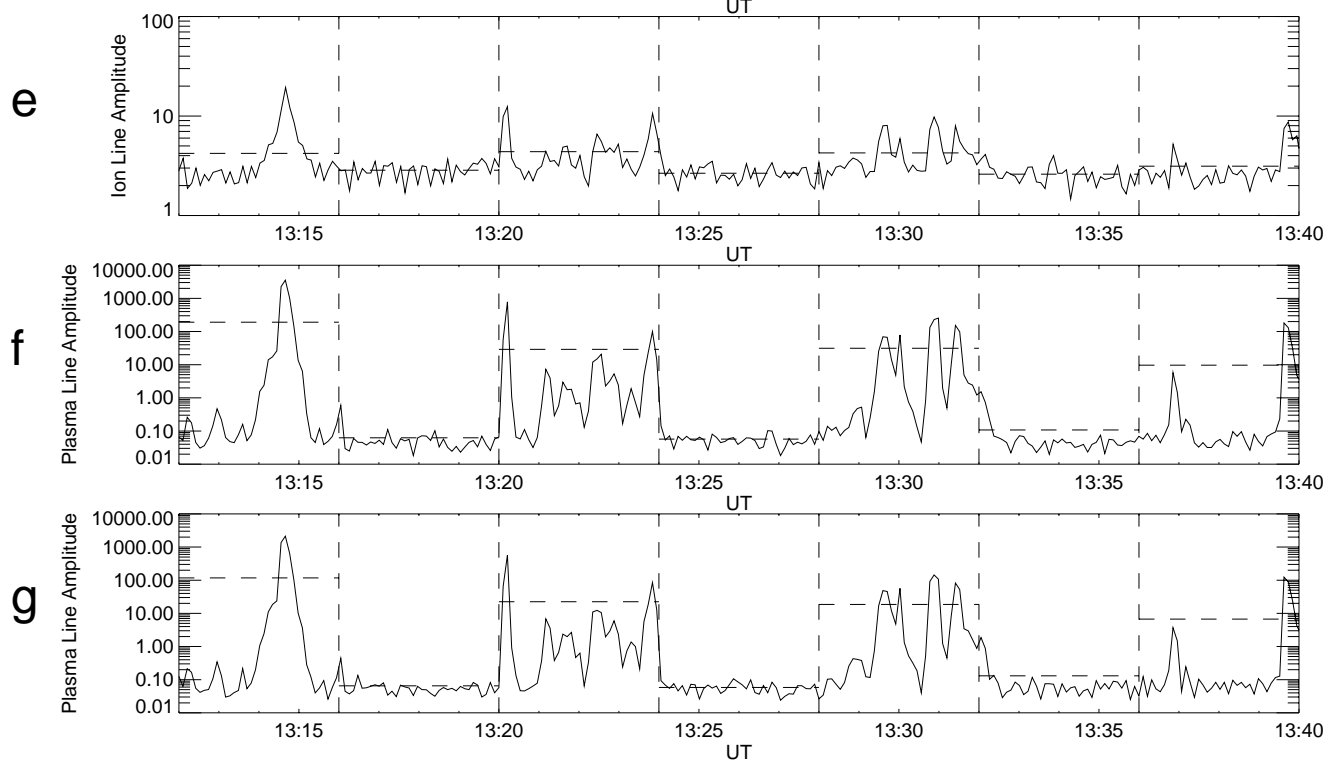

Fig. 17. Time series of amplitudes of CUTLASS Finland (panel a) and Iceland (panel b) backscatter powers, together with ESR ion- and plasma-lines for 13:12-13:40 UT, 1 October 2004. Panel (c) contains the upshifted ion-line; (d), the unshifted ion-line centre frequency; (e), the down shifted ion-line; (f), the upshifted plasma-line and (g), the downshifted plasma-line.

the rest of the heater on period. Only the constant power heater-on periods are useful for comparison with the SPEAR experiment and these periods are indicated by thick hori- zontal bars in Fig. 19. The upper panel of Fig. 19 exhibits the corresponding CUTLASS backscatter power from the heater-induced irregularities. The range from the CUTLASS 


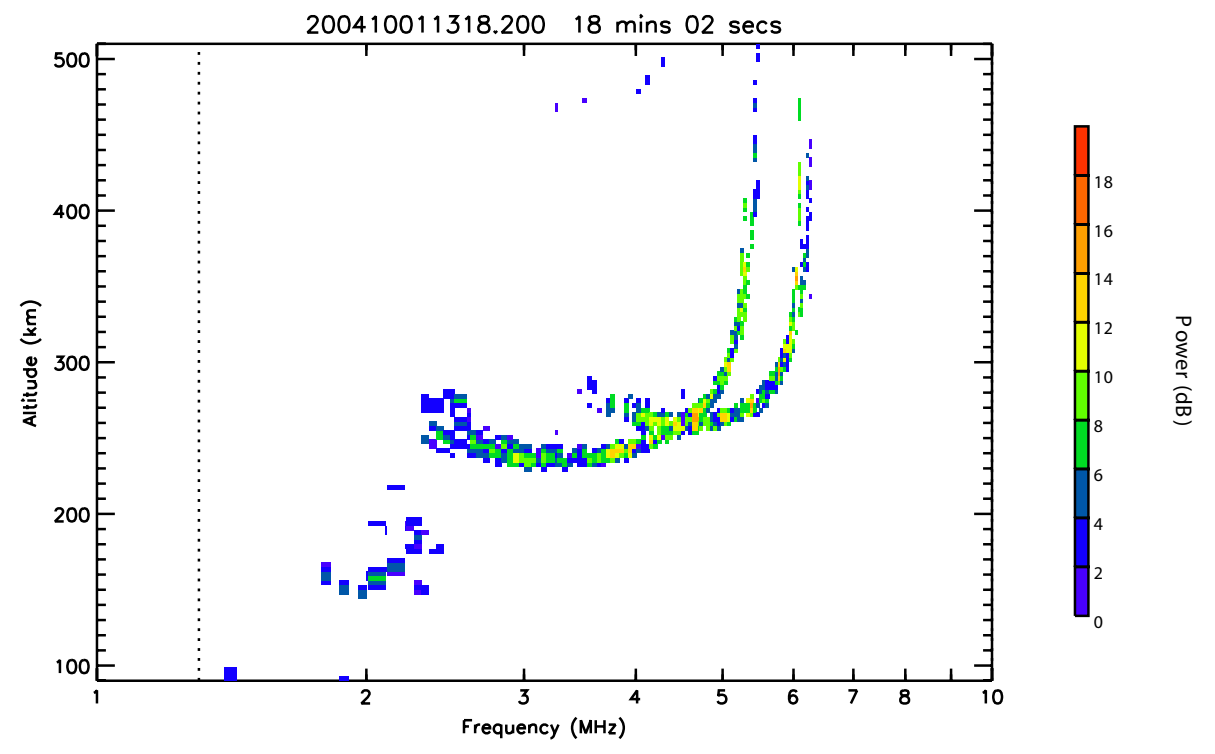

Fig. 18. Svalbard ionogram for 13:18 UT, 1 October 2004.

Finland site to that of the Tromsø heater is a little under $1000 \mathrm{~km}$. On the basis of the inverse cube power law already mentioned, this would mean that for the same scattering cross-section, and the same range cell size, CUTLASS backscatter power from Troms $\varnothing$ should be around 7 to 8 times that from SPEAR. The Troms $\varnothing$ heater power levels in Fig. 19 which best compare with those at SPEAR occur in the interval from 12:29 to 12:30 UT when the Troms $\varnothing$ heater was transmitting $15 \mathrm{MW}$ ERP. The corresponding enhancement in the CUTLASS backscatter was about 300 times above background. The corresponding levels for SPEAR are around 50 times (from Fig. 17). These levels are therefore roughly comparable with those which might be expected on the basis of the Troms $\varnothing$ results.

Also displayed in Fig. 19 (middle panel) are the central unshifted component of the ion-line backscatter data from the EISCAT UHF radar observed over the same period as the CUTLASS backscatter data. They exhibit very clearly the well-known ion-line overshoot phenomenon which has been a ubiquitous feature of heating experiments at Tromsø. It is typified by a strong enhancement of the ion-line power for a short period (usually no more than one data dump) immediately after heater turn on, followed by the (almost complete) disappearance of the enhancement for the rest of the time the heater is on. There are a few observations at Troms $\varnothing$ that indicate that the ion-line does not entirely disappear, but rather its amplitude falls to a level 10 to $20 \mathrm{~dB}$ below its initial peak (Djuth et al., 1994; Dhillon and Robinson, 2005). Ion-line overshoot effects are present at all ERP levels in Fig. 19, apart from the lowest of 3.5 MW which occurred between 12:21-12:22 UT. Notice also that there is no sign of any ion-line intensity enhancement after the overshoot spike in the Troms $\varnothing$ data in Fig. 19. Indeed, there is evidence that the ion-line power falls to levels below that during heater-off for a short time after the overshoot spike (although this lat- ter effect in probably due to a reduction in the UHF radar power output as a result of switching on the heater). On this basis it might be expected that a strong overshoot effect should be discernable in the SPEAR ESR data. From what has been reported above this is clearly not the case. There is no sign of systematic overshoot occurring in the SPEAR experiments. There are a few periods when it might be argued that there are signs of it. For example, in Fig. 9, just after 12:04 UT, in Fig. 13, just after 12:48 UT and in Fig. 17 just after 13:20 UT. However, these are the only times when it appears after SPEAR is turned on amongst many other times when SPEAR is turned on without any sign of overshoot. Furthermore, in all of these cases there are several further spikes in the ESR spectral power while SPEAR is on, which is not seen in the data from Tromsø (Fig. 19).

There is evidence that overshoot related phenomena are absent when the heater frequency is very close to a harmonic of the electron gyro-frequency (Honary et al., 1999), but under these conditions field-aligned striations are not generated either and hence no aspect-sensitive scatter would be seen. Indeed, as has been pointed out in the introduction, it has been argued that overshoot is caused by anomalous absorption of the heater wave due to the striations at an altitude below that from which the non aspect-sensitive scatter comes. This is clearly inconsistent with the data from the SPEAR experiments where several examples of simultaneous CUTLASS scatter and ESR scatter have been observed. Further, these results have been seen with several SPEAR operating frequencies, all of which have been chosen to avoid harmonics of the local electron gyro-frequency.

Another consideration in the context of the differences in heating effects seen at Troms $\varnothing$ and on Spitzbergen is the difference between the operating frequencies of the ESR and mainland EISCAT radars. The ESR works at frequencies close to $500 \mathrm{MHz}$, whereas the UHF radar responsible for the 


\section{CUTLASS AND EISCAT UHF DATA}

Power and lon Line Amplitude for 1220-1242 UT on 07/10/1997

a
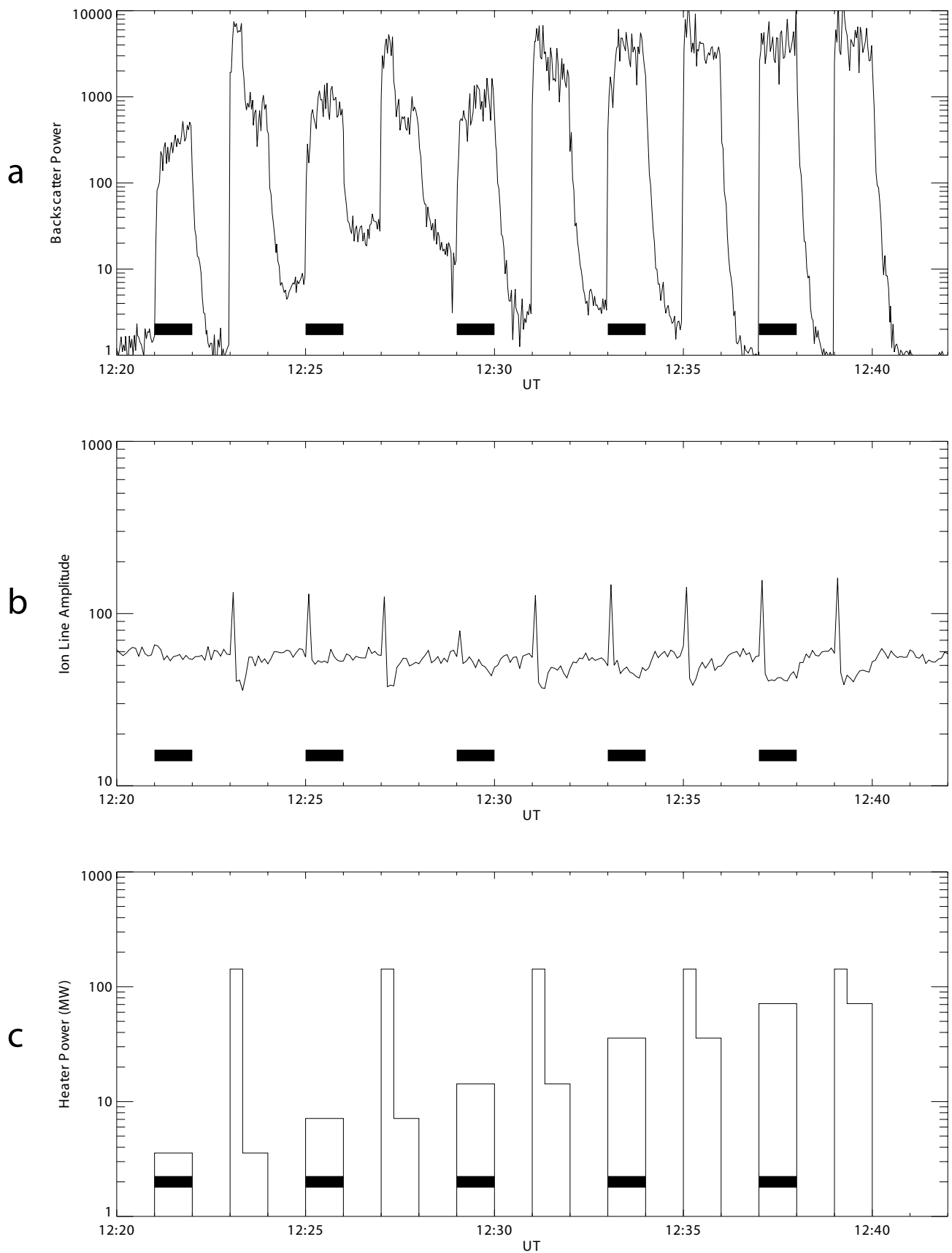

Fig. 19. Amplitudes of CUTLASS Finland backscatter (panel a) and the unshifted centre frequency of the EISCAT UHF (Troms $\varnothing$ ) ionline (panel b), together with the heater ERP levels (panel c) for 12:20-12:42 UT, 7 October, 1997. The EISCAT heater was operating at $4.544 \mathrm{MHz}$ and the time and range resolution of the ESCAT UHF radar data were $5 \mathrm{~s}$ and $22 \mathrm{~km}$, respectively.

data from Troms $\varnothing$ in Fig. 19 operates at $931 \mathrm{MHz}$. However, it is unlikely that these frequency differences explain the lack of overshoot in the ESR data, since the VHF EISCAT radar at Troms $\varnothing$, which operates at $224 \mathrm{MHz}$, also shows clear evidence of overshoot during heating experiments (Kohl et al., 1993). 
Yet another consideration which might help to explain the apparent lack of overshoot during the SPEAR experiments is the condition of the ionosphere itself. There is no doubt that during all of the SPEAR observations undertaken so far, the amplitude data appear to exhibit rather high levels of variability. The ionograms taken during both SPEAR campaigns also exhibited a level of spreading consistent with somewhat patchy plasma density distributions. This kind of structuring is to be expected in the polar ionosphere. This, together with the inevitable drifting of plasma under even weak natural electric fields or neutral winds would mean that plasma would not be constantly heated. The plasma density variability would also lead to strong local fluctuations in the electric field strength of the heater wave, due to focussing and defocusing effects, so that threshold levels required to trigger instabilities would only be exceeded for short periods within the whole of the 4-min on-period. Since the timeconstant for the excitation of the instabilities which give rise to the ESR scatter, as discussed in the introduction, is much shorter than that for the instabilities which give rise to the CUTLASS scatter, the ESR data would be expected to be much more variable than the CUTLASS data, because the instabilities involved would be continually being excited and decaying on short time-scales. The longer time-scales for the CUTLASS-related instabilities would have a relative smoothing effect on the CUTLASS backscatter amplitudes. This difference in variability could be further exaggerated in the ESR data by the small ESR beam cross-sectional area (about $1 \mathrm{~km}^{2}$ ) compared to the CUTLASS range-beam cell area (about $200 \mathrm{~km}^{2}$ ). Sampling over a larger area would also have a smoothing effect on the CUTLASS amplitude data, which is consistent with what is observed. However, this latter explanation of the lack of consistent overshoot during SPEAR heating is rather speculative and not entirely convincing. It thus must remain tentative in the absence of any other experimental evidence. Further observations of the type reported above are essential, hopefully involving more stable ionospheric conditions as we move towards solar maximum and also higher SPEAR transmitter powers, as confidence is gained in operating the new system.

Finally, as mentioned earlier, there is no evidence of bulk heating effects, such as large-scale changes in electron temperature or density occurring, so far, during heating experiments with SPEAR. Experience with the Troms $\emptyset$ heater has shown that large changes in these parameters can occur. Rietveld et al. (2003) have reported temperature changes of several thousands of degrees, although Robinson et al. (1997), reported much smaller bulk effects at similar heater powers. The response to heating depends on both the transmitted power of the heater and ionospheric conditions. The absence of large-scale heating effects with SPEAR is most likely due to a combination of lower transmitted power compared to the Troms $\varnothing$ heater as well as the generally more variable ionospheric conditions above Svalbard, already mentioned.
Acknowledgements. The SPEAR facility is supported on grant PPA/Z/O/2002/00668 by the Particle Physics and Astronomy Research Council (PPARC, UK). EISCAT is an International Association supported by Finland (SA), France (CNRS), the Federal Republic of Germany (MPG), Japan (NIPR), Norway (NFR), Sweden (VR) and the United Kingdom (PPARC). CUTLASS is supported jointly by the United Kingdom (PPARC) and Finland (FMI, Helsinki). CUTLASS operations at Leicester are funded by PPARC on grant PPA/R/R/1997/00256. We thank P. Chapman, now of the University of Lancaster, for his development work on the SPEAR system. We would also like to thank all the academic staff, technical team, postdoctoral research associate and postgraduate student members of the Radio and Space Plasma Physics Group, University of Leicester, whose hard work helped to make the SPEAR project possible.

Topical Editor T. Pulkkinen thanks F. Honary and M. Rietveld for their help in evaluating this paper.

\section{References}

Bond, G., Robinson, T. R., Eglitis, P., Wright, D. M., Stocker, A. J., Rietveld, M. T., and Jones, T. B.: Spatial observations by the CUTLASS coherent scatter radar of ionospheric modification by high power radio waves, Ann. Geophys., 15, 1412-1421, 1997, SRef-ID: 1432-0576/ag/1997-15-1412.

Dhillon, R. S., Robinson, T. R., and Wright, D. M.: Radar ACFs and turbulence characteristics from artificially generated fieldaligned irregularities, Geophys. Res. Lett., 29, 11-1-11-4, 2002.

Dhillon, R. S. and Robinson, T. R.: Observations of timedependence and aspect sensitivity of regions of enhanced UHF backscatter associated with RF heating, Ann. Geophys., 23, 7585,2005 ,

SRef-ID: 1432-0576/ag/2005-23-75.

Djuth, F. T., Stubbe, P., Sulzer, M. P., Kohl, H., Rietveld, M. T., and Elder, J. H.: Altitude characteristics of plasma turbulence excited with the Troms $\varnothing$ superheater, J. Geophys. Res., 99, 333339, 1994.

Fejer, J. A.: Ionospheric modification and parametric instabilities, Rev. Geophys., 17, 135-153, 1979.

Fejer, J. A. and Leer, E.: Purely-growing parametric instability in an inhomogeneous plasma, J. Geophys. Res., 77, 700-708, 1972.

Gordon, W. E. and Carlson Jr., H. C.: Arecibo heating experiments, Radio Sci., 9, 1041-1047, 1974.

Greenwald, R. A., Baker, K. B., Dudeney, J. R., Pinnock, M., Jones, T. B., Thomas, E. C., Villain, J.-P., Cerisier, J.-C., Senior, C., Hanuise, C., Hunsucker, R. D., Sofko, G., Koehler, J., Nielsen, E., Pellinen, R., Walker, A. D., Sato, N., and Yamagishi, H.: DARN/SuperDARN: A global view of the dynamics of highlatitude convection, Space Sci. Rev., 71, 761-796, 1995.

Honary, F., Robinson, T. R., Wright, D. M., Stocker, A. J., Rietveld, M. T., and McCrea, I.: First direct observations of the reduced striations at pump frequencies close to the electron gyroharmonics, Ann. Geophys., 17, 1235-1238, 1999,

SRef-ID: 1432-0576/ag/1999-17-1235.

Isham, B., Kofman, W., Hagfors, T., Nordling, J., Thidé, B., LaHoz, C., and Stubbe, P.: New phenomena observed by EISCAT during an RF ionospheric modification experiment, Radio Sci., 25, 251262, 1990.

Kohl, H., Kopka, H., Stubbe, P., and Rietveld, M. T.: Introduction to ionospheric heating experiments at Troms $\varnothing$-II. Scientific problems, J. Atmos. Terr. Phys., 55, 601-613, 1993. 
Lester, M., Chapman, P. J., Cowley, S. W. H., Crooks, S. J., Davies, J. A., Hamadyk, P., McWilliams, K. A., Milan, S. E., Parsons, M. J., Payne, D. B., Thomas, E. C., Thornhill, J. D., Wade, N. M., Yeoman, T. K., and Barnes, R. J.: Stereo CUTLASS: A new capability for the SuperDARN radars, Ann. Geophys., 22, 459473, 2004,

\section{SRef-ID: 1432-0576/ag/2004-22-459.}

Minkoff, J., Kugelman, P., and Weissman, I.: Radio frequency scattering from a heated ionospheric volume, 1, VHF/UHF fieldaligned and plasma-line backscatter measurements, Radio Sci., 9, 941-955, 1974.

Rietveld, M. T., Isham, B., Kohl, H., La Hoz, C., and Hagfors, T.: Measurements of HF-enhanced plasma and ion lines at EISCAT with high-altitude resolution, J. Geophys. Res., 105, 7429-7439, 2000.

Rietveld, M. T., Kosch, M. J., Blagoveshchenskaya, N. F., Kornienko, V. A., Leyser, T. B., and Yeoman, T. K.: Ionospheric electron heating, optical emissions and striations induced by powerful HF radio waves at high latitudes: aspect angle dependence, J. Geophys. Res., 108, 1141, doi:10.1029/2002JA009543, 2003.

Rietveld, M. T., Kosch, M. J., Blagoveshchenskaya, N. F., Kornienko, V. A., Leyser, T. B., and Yeoman, T. K.: Correction to Rietveld et al. (2003), J. Geophys. Res., 109, A04306, doi:10.1029/2004JA010460, 2004.

Robinson, T. R.: The heating of the high latitude ionosphere by high power radio waves, Phys. Rep. 179, 79-209, 1989.
Robinson, T. R.: Effect of multiple scatter on the propagation and absorption of electromagnetic waves in a field-aligned-striated magnetoplasma: Implications for ionospheric modification experiments, Ann. Geophys., 20, 41-55, 2002,

SRef-ID: 1432-0576/ag/2002-20-41.

Robinson, T. R., Stocker, A. J., Bond, G., Eglitis, P., Wright D. M., and Jones, T. B.: O and X mode heating effects observed simultaneously with the CUTLASS and EISCAT radars and low power HF diagnostics at Tromsø, Ann. Geophys., 15, 134-136, 1997.

Robinson, T. R., Strangeway, R., Wright, D. M., Davies, J. A., Horne, R. B., Yeoman, T. K., Stocker, A. J., Lester, M., Rietveld, M. T., Mann, I. R., Carlson, C. W., and McFadden, J. P.: FAST observations of ULF waves injected into the magnetosphere by means of modulated RF heating of the auroral electrojet, Geophys. Res. Lett., 27, 3165-3168, 2000.

Showen, R. L.: The spectral measurement of plasma lines, Radio Sci., 14, 503-508, 1979.

Wright, D. M., Davies, J. A., Robinson, T. R., Chapman, P. J., Yeoman, T. K., Thomas, E. C., Lester, M., Cowley, S. W. H., Stocker, A. J., Horne, R. B., and Honary, F.: Space Plasma Exploration by Active Radar (SPEAR): an overview of a future facility, Ann. Geophys., 18, 1248-1255, 2000,

SRef-ID: 1432-0576/ag/2000-18-1248.

Yeoman, T. K., Wright, D. M., Robinson, T. R., and Rietveld, M. T.: High spatial and temporal resolution observations of an impulsedriven field line resonance in backscatter radar artificially generated with the Troms $\varnothing$ heater, Ann. Geophys., 15, 634-644, 1997, SRef-ID: 1432-0576/ag/1997-15-634. 